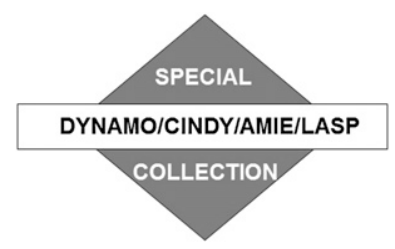

\title{
The Relationship between the ITCZ and MJO Initiation over the Indian Ocean
}

\author{
RACHEL C. ZELINSKY \\ University of Miami, Miami, Florida \\ CHIDONG ZHANG \\ NOAA/PMEL, Seattle, Washington \\ Chuntao LiU \\ Texas A\&M University-Corpus Christi, Corpus Christi, Texas
}

(Manuscript received 19 November 2018, in final form 8 May 2019)

\begin{abstract}
Understanding convective initiation of the Madden-Julian oscillation (MJO) remains an unmet challenge. MJO initiation has been perceived as a process starting from a convectively suppressed large-scale condition with gradual growth of shallow convection to congestus and to deep convective and stratiform systems that cover a large-scale area. During the DYNAMO field campaign over the Indian Ocean, MJO initiation was observed to start from an existing intertropical convergence zone (ITCZ) south of the equator. This raises a question of what possible role the ITCZ may play in convective initiation of the MJO. This study addresses this question through analysis of satellite observations of precipitation and a global reanalysis product. By setting several criteria, MJO and ITCZ events were objectively identified and grouped according to whether MJO initiation was immediately preceded by an ITCZ. The results demonstrate that an ITCZ is neither a necessary nor sufficient condition for convective initiation of the MJO. Nonetheless, evolution of the largescale circulation, moisture, and convective characteristics during MJO initiation can be different with and without a preexisting ITCZ. Convective growth begins gradually before and during MJO initiation when there is a preexisting ITCZ whereas it is abrupt and slightly delayed without a preexisting ITCZ. Such differences are presumably related to the existing large-scale moist condition of the ITCZ. The results from this study suggest that there are multiple mechanisms for convective initiation of the $\mathrm{MJO}$, which should be considered in theoretical understanding of the MJO.
\end{abstract}

\section{Introduction}

The Madden-Julian oscillation (MJO; Madden and Julian 1971, 1972) is the strongest source of intraseasonal variability in the tropics (Zhang 2005). It is an important link between weather and climate (Zhang 2013). The MJO provides a major source of subseasonal (2-12 weeks) predictability (Waliser et al. 2003), making it a key target for the improvement of subseasonal-to-seasonal (S2S) prediction (Vitart 2009; Zhang 2013). Theories have been developed to explain the existence and eastward propagation of the MJO. For example, the moisture mode theory indicates that the propagation of the MJO

Corresponding author: Rachel C. Zelinsky, rsodowsky@ rsmas.miami.edu is the result of moisture advection, and its growth is due to radiation-cloud interaction and background moisture (Maloney et al. 2010; Sobel and Maloney 2013; Adames and Kim 2016). MJO multiscale theory points to the fluxes of momentum and potential temperature between scales as the basis for MJO propagation and maintenance (Biello and Majda 2005). A recent trio-interaction theory emphasizes the role of feedbacks among boundary layer frictional convergence, moisture, and wave dynamics (Wang et al. 2016). These and other theories (e.g., Majda and Stechmann 2009; Yang and Ingersoll 2013; Fuchs and Raymond 2017) explain the propagation and scale selection of the MJO. No theory currently explains why it initiates in the first place or why it initiates over the Indian Ocean most of the time (Zhang and Ling 2017). 
There are hypotheses on convective initiation of the MJO. One hypothesis is that extratropical variability may be a trigger for initiation (Hsu et al. 1990; Lin et al. 2007; Ray and Zhang 2010). These studies found evidence in observations and numerical simulations that input from the extratropics can lead to MJO initiation. Another hypothesis relates MJO convective initiation to circumnavigating perturbations in the upper troposphere, which modify vertical motions over the Indian Ocean that affect vertical transport of moisture (Powell and Houze 2015). In the local discharge-recharge process hypothesis, shallow convection begins to moisten and heat the environment during the suppressed phase; eventually the environment becomes sufficiently moist to support deep convection in the active phase of the MJO (Xu and Rutledge 2015).

Despite the observed importance of the MJO to the weather-climate system, most global climate models (GCM) are unable to reliably forecast or reproduce the MJO (Hung et al. 2013; Jiang et al. 2015). This could be partially related to their difficulty of reproducing MJO initiation, which mainly occurs over the tropical Indian Ocean where a large packet of deep convection forms and begins to move eastward (Ling et al. 2013). For these reasons, it is extremely important to advance our understanding of the processes governing MJO initiation.

The intertropical convergence zone (ITCZ) is a semipermanent band of clouds and rainfall that forms where the trade winds converge near the equator. The ITCZ is a major source of latent heating in the tropics that drives the meridional-vertical circulations. In the Indian Ocean, the ITCZ generally sits south of the equator (Schneider et al. 2014) but a second ITCZ can develop north of the equator to form a double ITCZ (Zhang 2001).

Both MJO initiation and the ITCZ are prominent phenomena over the Indian Ocean. But they were never thought to be related to each other until the Dynamics of the MJO (DYNAMO ${ }^{1}$ ) field campaign, which took place across the equatorial central Indian Ocean from October 2011 to March 2012 with a goal of expediting the progress of understanding and predicting MJO initiation over the Indian Ocean (Yoneyama et al. 2013). Before DYNAMO, the perception of MJO initiation was that it started from a large-scale condition of suppressed convection over the Indian Ocean, which gradually transitioned to active convection (e.g., Kemball-Cook and Weare 2001;

\footnotetext{
${ }^{1}$ This is a joint project with CINDY2011 (Cooperative Indian Ocean Experiment on Intraseasonal Variability in the Year 2011), AMIE (ARM MJO Investigation Experiment), and LASP (Littoral Air-Sea Process).
}

Seo 2003; Matthews 2008). One surprising outcome of DYNAMO was evidence of a possible connection between the ITCZ and MJO initiation: Active convection was observed in the ITCZ immediately prior to convective initiation of two observed $\mathrm{MJO}$ events, and there was no large-scale condition of suppressed convection over the broad tropical Indian Ocean before MJO initiation (Johnson and Ciesielski 2013; Yoneyama et al. 2013; Kerns and Chen 2014; Ciesielski et al. 2018).

The transition from an ITCZ to MJO initiation may be one of large-scale relocation, expansion, and intensification of convection with no change in statistical convective characteristics, or a convective regime change with a significant shift in convective statistics. Satellite observations, for example, those of Tropical Rainfall Measurement Mission (TRMM), have been used to document global characteristics of tropical precipitation system (e.g., Liu and Zipser 2013; Houze et al. 2015). Previous studies have described convection during the MJO life cycle in four stages: suppressed, developing, mature, and decaying stages (Morita et al. 2006). Studies using TRMM and surface based radars have shown the upscale growth of isolated deep convective cells into mesoscale convective systems (MCSs) as part of the convective characteristics of the MJO (Barnes and Houze 2013; Zuluaga and Houze 2013; $\mathrm{Xu}$ and Rutledge 2015). However, the specific characteristics of convection in the ITCZ and MJO over the Indian Ocean, which are two types of large-scale phenomena of organized convection, have not been directly compared.

The objective of this study is to explore the nature of the transition from an ITCZ to convective initiation of the MJO (hereafter briefly as MJO initiation) over the Indian Ocean. We attempt to address two questions. 1) Is there any identifiable difference between MJO initiation with and without an immediately preceding ITCZ? 2) When the MJO is preceded by an ITCZ, how might the ITCZ contribute to its initiation?

This study is based on satellite data and a global data assimilation product (section 2). ITCZ and MJO events were objectively defined after several parameters were subjectively chosen (section 3). Results from this study demonstrate that changes are present in the large-scale distributions of precipitation and circulations, along with convective characteristics, during convective initiation of the MJO with and without a preexisting ITCZ (section 4). A discussion of possible roles of the ITCZ in MJO initiation over the Indian Ocean is provided (section 5).

\section{Data}

\section{a. Precipitation data}

Rain-rate estimates from version 7 of TRMM 3B42 (Huffman and Bolvin 2014) are used to identify the 
ITCZ and MJO initiation for 1998-2013. The horizontal resolution of the data is $0.25^{\circ} \times 0.25^{\circ}$ and its temporal resolution $3 \mathrm{~h}$. The data were converted to 5-day running means in this study to remove irrelevant high-frequency variability for the identification of the ITCZ and MJO initiation.

\section{b. Precipitation features}

Cloud and rainfall statistics are calculated to generate the TRMM Precipitation Features (PFs) by Liu et al. (2008). PFs are defined by grouping TRMM Precipitation Radar pixels [17.96 (20.35) km² before (after) the satellite boost which occurred in 2002] with $20-\mathrm{dB} Z$ surface reflectivity or TMI $85-\mathrm{GHz} \mathrm{Po}-$ larization Corrected Temperature colder than $250 \mathrm{~K}$ (Spencer et al. 1989). All 16 years of data (1998-2013) are used to count the number of PFs occurring during identified MJO or ITCZ events. However, to keep the area of the Precipitation Radar pixels consistent when calculating other PF statistics, we only use data after the TRMM satellite boost (2002-13) for the other PF statistics.

The size and rain rate can be determined for every individual PF. The number of pixels for a PF multiplied by the pixel area determines the size of the PF. The pixels are also classified as stratiform or convective by the 2A23 algorithm as described by Awaka et al. (1998), so the size of the convective and stratiform parts of a PF can be determined. There are occasionally unclassified pixels $(<1 \%)$, and the sum of stratiform and convective pixel numbers and sizes of a given $\mathrm{PF}$ is not necessarily equal to its total.

\section{c. Reanalysis}

Daily ERA-Interim data (Dee et al. 2011) are used to examine the large-scale environment (relative humidity and wind patterns) associated with the ITCZ and MJO. The spatial resolution of the data is $0.75^{\circ} \times 0.75^{\circ}$ and the vertical resolution is $25 \mathrm{hPa}$ between 1000 and $750 \mathrm{hPa}$, $50 \mathrm{hPa}$ between 750 and $250 \mathrm{hPa}$, and $25 \mathrm{hPa}$ between 250 and $100 \mathrm{hPa}$.

\section{Methods}

\section{a. Identifying the $M J O$}

The MJO is identified by tracking the eastward propagation of intraseasonal (30-90 days) positive rainfall anomalies across the Indian Ocean along the equator. This tracking method was first introduced by Ling et al. (2014) and further described in Zhang and Ling (2017). On a time-longitude diagram, an MJO track is defined as the line along which the integrated rainfall anomaly is maximized among all possible options representing eastward propagation passing a given longitude at a given day. For an MJO event, the eastward propagation speed must be between 3 and $7 \mathrm{~ms}^{-1}$. A convective initiation day of the MJO (hereafter simply as MJO initiation day) is the first day when precipitation anomalies averaged over the equatorial Indian Ocean $\left(15^{\circ} \mathrm{S}-15^{\circ} \mathrm{N}\right.$, $60^{\circ}-90^{\circ} \mathrm{E}$ ) is more than one standard deviation along its track. There are $40 \mathrm{MJO}$ events thus identified during 1998-2013.

\section{b. Identifying the ITCZ}

Despite the importance and prominent appearance of the ITCZ, there is no single method to identify it that has been commonly used by the research community. Waliser and Gautier (1993) applied a subjective approach to identify the ITCZ using the highly reflective cloud (HRC) data to indirectly estimate precipitation. Wang and Magnusdottir (2006) identified the ITCZ subjectively by looking for an elongated band of precipitation in visible satellite imagery and considered the ITCZ deep if the event showed up on IR imagery. Bain et al. (2011) improved upon the identification method of Wang and Magnusdottir (2006) by applying three criteria to an automated statistical model. Their three criteria are 1) zonal elongation, 2) cloudiness, and 3) the tropical feature must be unconnected to other regions of cloudiness based on visible, IR, and total perceptible water data from satellites. This method attempts to eliminate the subjective nature of human identification. However, its parameters still need to be empirically determined for the model. Haffke et al. (2016) used a statistical model to determine the daily state of the ITCZ from over 30 years of satellite data. This method spatially identifies and segments the convective zones in the equatorial Pacific and creates time series from satellite images to classify the state of the ITCZ. Wodzicki and Rapp (2016) used ERA-Interim data and TRMM TMI rain estimates in their identification method. The location of the ITCZ was determined by negative divergence in the $1000-850-\mathrm{hPa}$ layer, and $850-\mathrm{hPa}$ wet-bulb temperature was used to separate tropical features from extratropical features. The rain estimate from the TMI was used to determine the width of the ITCZ. The boundary of the ITCZ was selected when the rain rate in a grid box fell below a threshold selected by the authors. All these methods of ITCZ identification require certain subjectivity even when an objective algorithm is implemented.

Here, we introduce a different method to identify precipitation associated with the ITCZ. Our study is primarily interested in precipitation associated with the ITCZ, rather than the low-level convergence that defines it. Therefore, our method focuses on identifying 


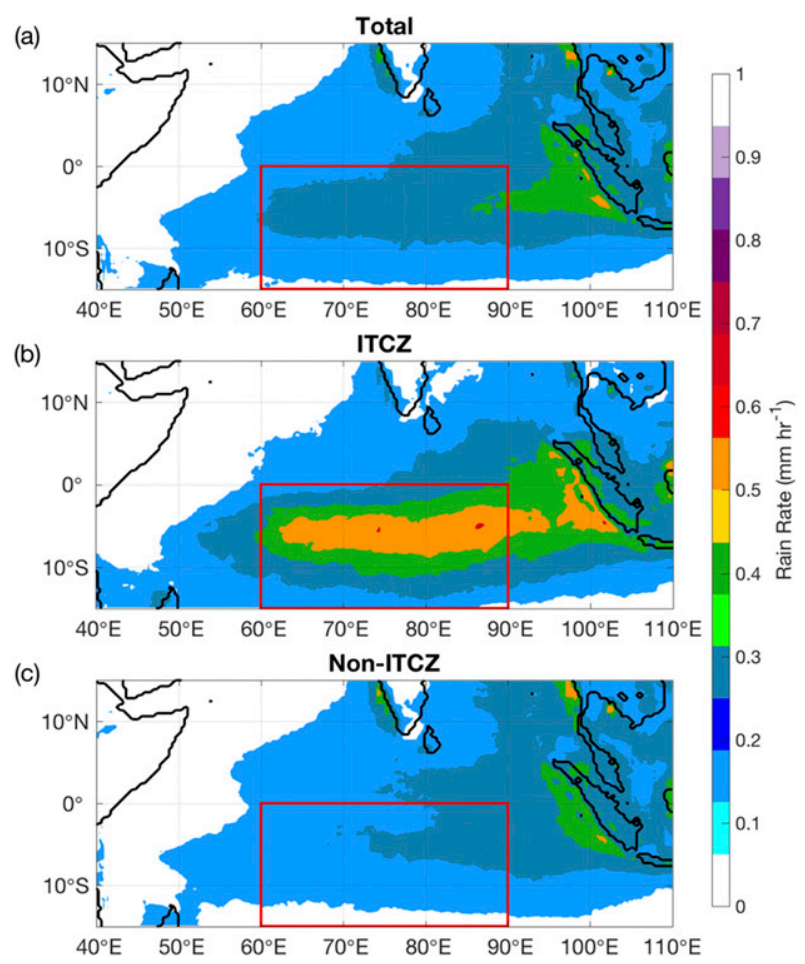

FIG. 1. Composites for TRMM rain-rate distributions over the Indian Ocean during 1998-2013 for (a) total, (b) all ITCZ days, and (c) all non-ITCZ days. Red box outlines the ITCZ domain $\left(0^{\circ}-\right.$ $\left.15^{\circ} \mathrm{S}, 60^{\circ}-90^{\circ} \mathrm{E}\right)$

precipitation features associated with the ITCZ using the same TRMM precipitation datasets used to identify and track MJO events. In this method, several criteria are applied to the TRMM rainfall data to identify a narrow, zonally elongated band of rain south of the equator, which is considered as a sign of the ITCZ. The large-scale conditions around the ITCZ (from the global reanalysis) are treated as independent variables not used in the ITCZ identification.

Mean rainfall for the years 1998-2013 over the tropical Indian Ocean shows an ITCZ like distribution with its maximum south of the equator with a continuous spread of decreasing rainfall toward both the south and north (Fig. 1a). This broad pattern of precipitation is not what we normally recognize as an ITCZ, which should be a zonally elongated narrow band. However, it suggests a climatological latitudinal location (between the equator and $\left.15^{\circ} \mathrm{S}\right)$ and zonal range $\left(60^{\circ}-90^{\circ} \mathrm{E}\right)$ of the ITCZ. Precipitation signals of the ITCZ are identified within a longitudinal range of $60^{\circ}-90^{\circ} \mathrm{E}$ and a latitudinal range of $0^{\circ}-15^{\circ} \mathrm{S}$ (red box in Fig. 1a). While the choice of the exact latitude and longitude ranges was somewhat subjective, these ranges capture the strongest mean rainfall over the Indian Ocean and avoid the complicated rainfall pattern near the Indo-Pacific
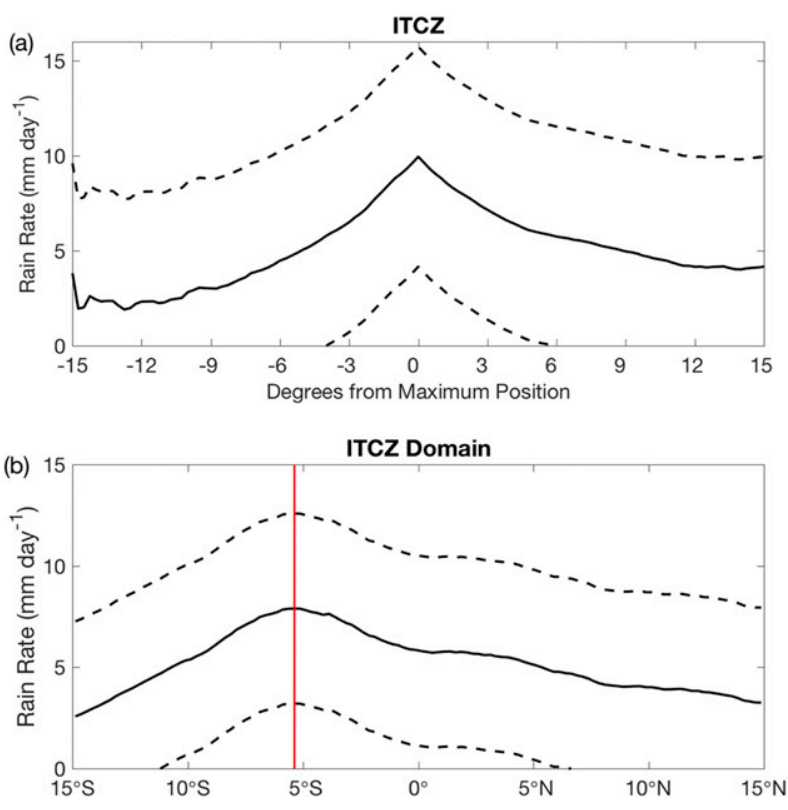

FIG. 2. Longitudinally $\left(60^{\circ}-90^{\circ} \mathrm{E}\right)$ averaged meridional distribution (solid lines) and plus and minus one standard deviation (dashed) of the rain rates for (a) the ITCZ (all rainfall peaks are at 0 ) and (b) the ITCZ domain. Vertical straight line in (b) marks the climatological latitude of ITCZ peak rainfall.

Maritime Continent that is oriented along the coast of Sumatra.

An average is then taken over the longitudinal range $60^{\circ} \mathrm{E}-90^{\circ} \mathrm{E}$ for each day. From each daily meridional distribution, the latitude of the peak rain rate is located. Days where the peak rain rate is outside the ITCZ domain (south of $15^{\circ} \mathrm{S}$ or north of the equator) are excluded from further analysis. This criterion removed 1674 days (roughly 30\%) from the analysis period of 1998-2013. A composite of the meridional distribution of rainfall is produced by averaging the daily meridional distribution with the latitudes of their peak rain rates aligned as the reference point $(0)$. This meridional distribution, treated as that of the ITCZ, shows a sharp peak at the reference point (Fig. 2a). In contrast, the climatological mean of the meridional distribution of total rainfall for the ITCZ domain shows a rounded peak (Fig. 2b). This contrast indicates that the latitudinal location of the peak rainfall associated with the ITCZ varies considerably, whereas the rain rate of an ITCZ always decreases sharply away from its peak on both sides.

The rest of this method applies the following steps to the ITCZ domain.

1) A "non-ITCZ day" is identified when the peak rain rate of its daily mean meridional distribution is within the range of its climatological variability. 

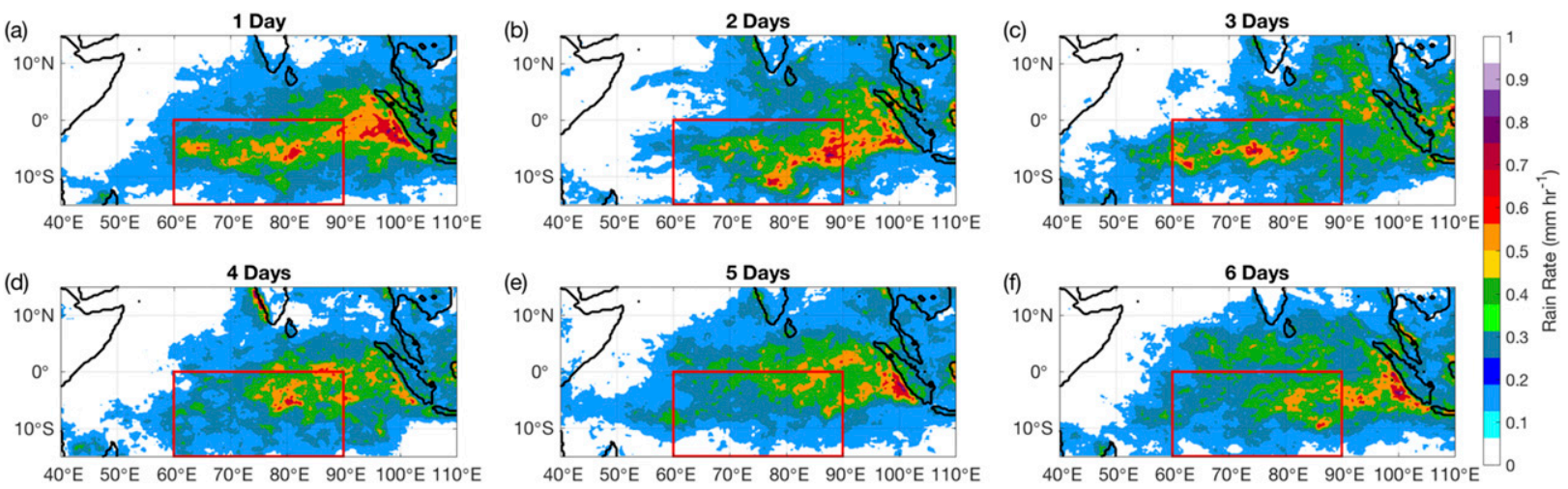

FIG. 3. Composites of rain-rate distributions for (a)-(f) consecutive 1-6 non-ITCZ days, respectively. Red box outlines the ITCZ domain $\left(0^{\circ}-15^{\circ} \mathrm{S}, 60^{\circ}-90^{\circ} \mathrm{E}\right)$.

This climatological range is $25.4 \mathrm{~mm}$ day $^{-1}$, which is the composite peak of the rain rate within the ITCZ domain ( $9.9 \mathrm{~mm} \mathrm{day}^{-1}$ in Fig. 2a) plus one standard deviation at the ITCZ peak $\left(15.5 \mathrm{~mm} \mathrm{day}^{-1}\right.$ in Fig. 2a). This definition of the climatological range might be subjective, but it ensures that the ITCZ is a prominent, not an averaged, feature of rainfall. This criterion removed 2630 days (roughly $60 \%$ ) from the remaining days in the analysis period.

2) In the climatological mean meridional distribution of rainfall, the rain rate decreases from $7 \mathrm{~mm} \mathrm{day}^{-1}$ at the peak at $5.4^{\circ} \mathrm{S}$ to $5.25 \mathrm{~mm} \mathrm{day}^{-1}$ at the equator (solid line in Fig. 2b). This $25 \%$ decrease is taken as a threshold for the minimum decreasing rate of ITCZ rainfall from its peak. In other words, if in a daily mean meridional distribution of rainfall the rain rate decreases less than $25 \%$ from its peak to the equator, this day is considered as a non-ITCZ day. This ensures that the ITCZ is identified only as a narrow band of precipitation. This criterion removed 220 days (roughly 14\% ) from the remaining days in the analysis period.

From steps 1 and 2, an "ITCZ day" is selected if the peak rain rate of its daily mean meridional distribution of rainfall is greater than the composite peak plus one standard deviation in Fig. $2 \mathrm{a}\left(15.5 \mathrm{~mm} \mathrm{day}^{-1}\right)$ and the rain rate decreases from the peak to the equator more than $25 \%$. In total, 1403 ITCZ days (roughly $25 \%$ ) were thus identified from the analysis period.

3) Consecutive ITCZ days are defined as a single ITCZ events. The ITCZ is known for its daily fluctuations (Wang and Magnusdottir 2006; Haffke et al. 2016). ITCZ structures in rainfall are very visible in some non-ITCZ days, especially those that last only few days (Figs. 3a-c). Some ITCZ events include 1-3 days of non-ITCZ days where rainfall distributions failed to meet criterion 1 or 2 by a small margin. When ITCZ structures disappear for 3 or more consecutive non-ITCZ days (Figs. 3d-f), the ITCZ event is concluded. The allowance of 1-3 non-ITCZ days in a single ITCZ event was subjective but was based on the observed nature of daily fluctuations of an ITCZ event. There are 212 ITCZ events thus identified from the analysis period.

The composite of rainfall for all ITCZ days demonstrates an anticipated typical ITCZ structure over the Indian Ocean that is narrow, zonally elongated, and centered near $5^{\circ} \mathrm{S}$ (Fig. 1b). In comparison, the composite of rainfall for all non-ITCZ days does not show any distinct meridional structure, except a vague sign of a double ITCZ (Fig. 1c). This result increases confidence that our proposed method correctly identifies ITCZ events. Our method was designed to capture the ITCZ convection over the southern Indian Ocean that is strong and unambiguous. It may not capture a weak ITCZ or an ITCZ at or north of the equator. Slight changes in the criteria do not significantly affect the ITCZ statistics discussed in section 4 .

\section{Results}

\section{a. Simple statistics}

An ITCZ event may last from 1 day to more than 20 days. The majority ( $87.5 \%$ ) of ITCZ events last less than 10 days (Fig. 4a). Those longer than 10 days are more likely to occur in boreal winter than the other seasons (Fig. 4b). The structure and strength of ITCZ events vary with their durations. In December, for example, ITCZ rainfall tends to be stronger and wider for events that last longer while its zonally elongated pattern persists regardless of the duration (Fig. 5). There are more ITCZ days in January and February 

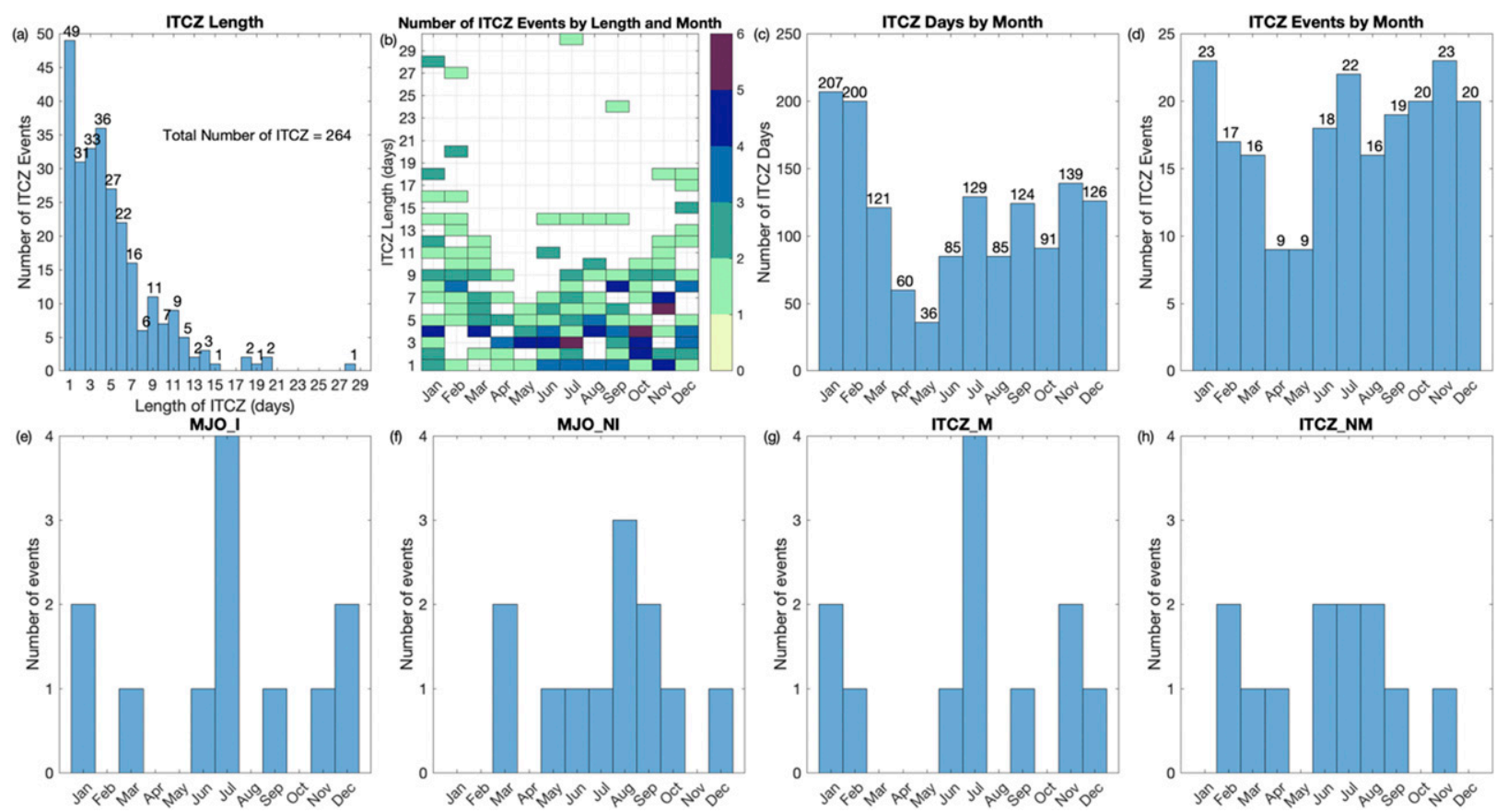

FIG. 4. (a) Number distribution of the length (days) of ITCZ events for 1998-2013. (b) Number of ITCZ events as a function of their length (days) and month or 1998-2013. (c) Number of ITCZ days by month for 1998-2013. (d) Number of ITCZ events by month for 1998-2013. (e) The number of MJO preceded by an ITCZ by month. (f) The number of MJO not preceded by an ITCZ by month. (g) The number of ITCZ events followed by an MJO by month. (h) The number of ITCZ events not followed by an MJO by month.

than other months and the least ITCZ days in April and May (Fig. 4c). Consequently, there are the smallest number of ITCZ events in April and May (Fig. 4d). Yearto-year fluctuations in the number of ITCZ events appear to be random. The Indian Ocean dipole and ENSO have been shown to have influence on weather and climate over the Indian Ocean (Ashok et al. 2001, 2004).
However, we found no obvious connection between the dipole mode index or Niño-3.4 index and the number of ITCZ events over the Indian Ocean.

One intriguing question from the DYNAMO field campaign is how often an ITCZ directly leads to MJO initiation. Out of the $40 \mathrm{MJO}$ events identified in this study, 12 initiated over the Indian Ocean with an (a)

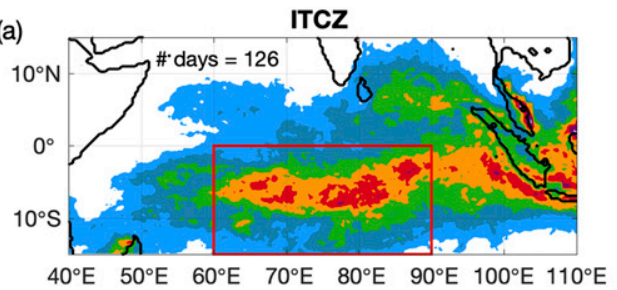

(c)

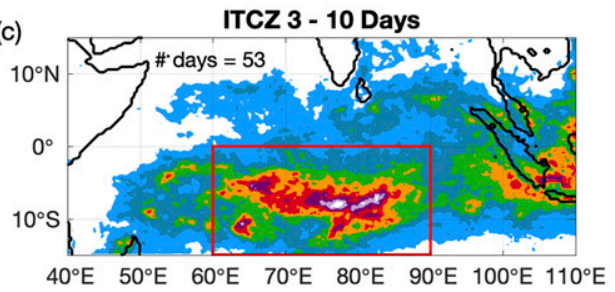

(b)

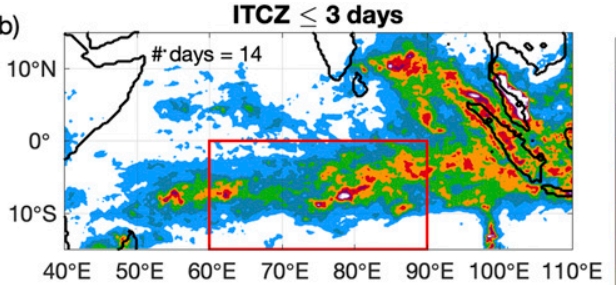

(d)

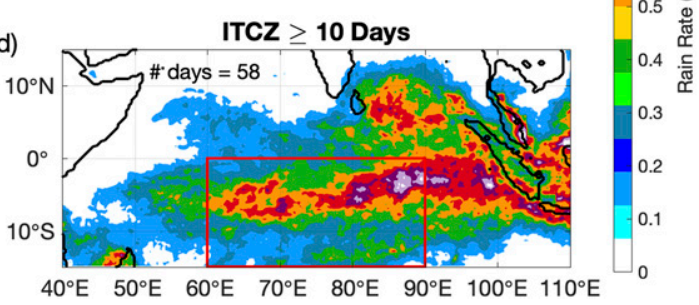

FIG. 5. Averaged rainfall patterns for (a) all ITCZ events, (b) ITCZ events $<3$ days, (c) ITCZ event of 3-10 days, and (d) ITCZ events $>10$ days in December. Red box outlines the ITCZ domain $\left(0^{\circ}-15^{\circ} \mathrm{S}\right.$, $\left.60^{\circ}-90^{\circ} \mathrm{E}\right)$. 

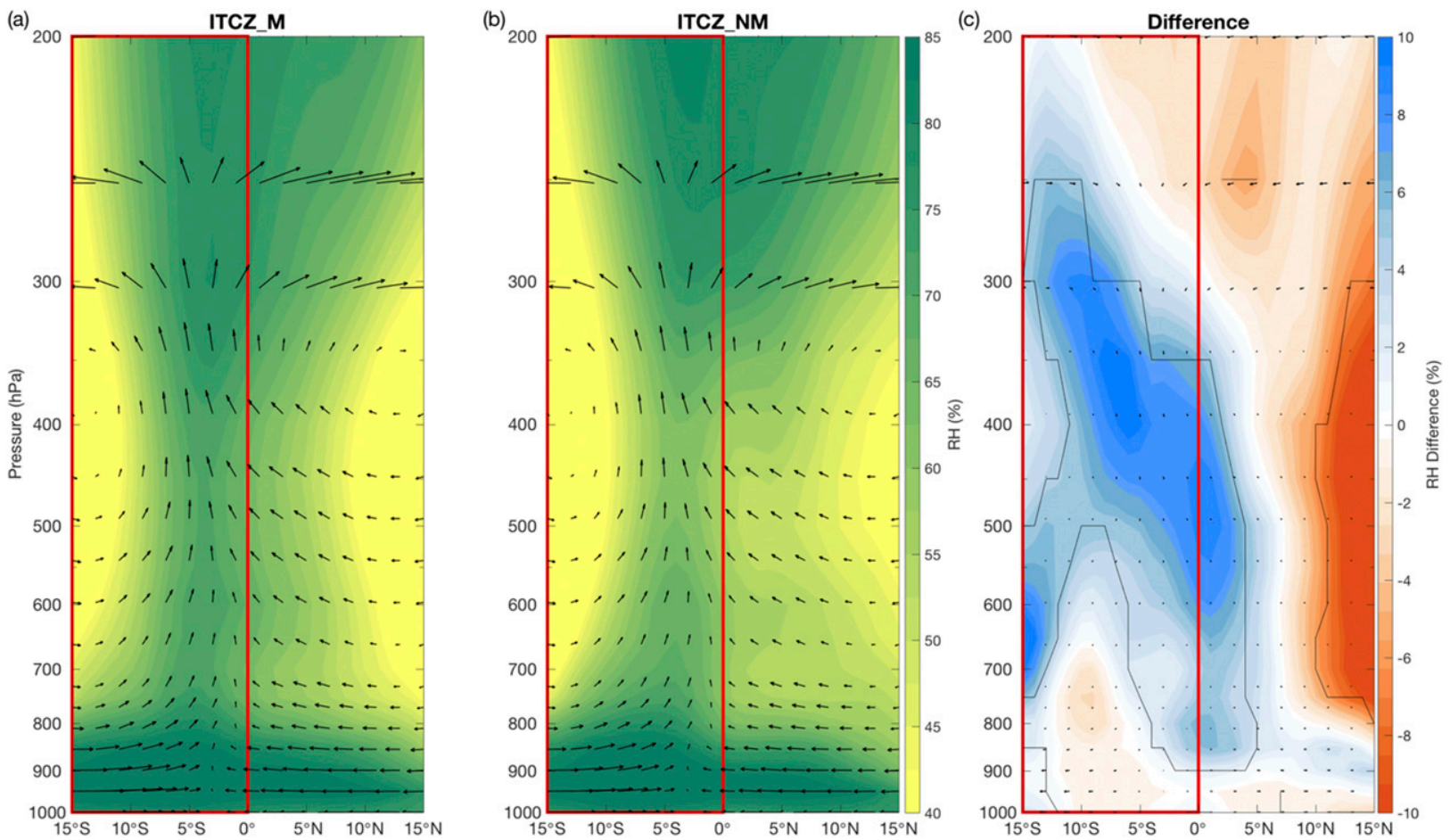

FIG. 6. Meridional-vertical cross sections (averaged over $60^{\circ}-90^{\circ} \mathrm{E}$ ) for wind ( $v-w$ vectors) and RH (colors) for (a) ITCZ events followed by MJO initiation (ITCZ_M) and (b) ITCZ events not followed by MJO initiation (ITCZ_NM). (c) Their difference [(a) minus (b)]. Contours in (c) outline areas where RH is significantly different at the $95 \%$ significance level. Vertical velocity is multiplied by 50 to make it visible. Red box outlines the ITCZ domain $\left(0^{\circ}-15^{\circ} \mathrm{S}, 60^{\circ}-90^{\circ} \mathrm{E}\right)$.

immediately preceding ITCZ. Eight other MJO events occurred within 10 days of the end of an ITCZ event. These suggest a potential relationship between the ITCZ and MJO initiation might exist for about $50 \%$ of the MJO events initiated over the Indian Ocean. The 12 MJO events that initiated immediately following an ITCZ day can confidently be considered as associated with the ITCZ. Their convective and large-scale characteristics will be compared to those of their preceding ITCZ. These MJO events will hereafter be denoted as MJO associated with an ITCZ or MJO_I. For an even comparison, 12 MJO events with the greatest number of days ( $>16$ days) between their initiation and the end of a previous ITCZ were selected as MJO events not associated with the ITCZ (MJO_NI). Equivalently, there are the 12 ITCZ events immediately followed by MJO_I initiation (ITCZ_M) and the 12 ITCZ events that occur at least 16 days before MJO_NI (ITCZ_NM) that will be used as ITCZ groups for the analysis.

The MJO has seasonality with the main peak in activity occurring during the boreal winter and a secondary peak occurring in boreal summer (Zhang and Dong 2004). About $50 \%$ of the MJO in both MJO groups (six for MJO_I and seven for MJO_NI) used in the study initiated during boreal summer months
(May-September) (Figs. 4e-h). If there are seasonal effects in the following analysis, then it should be equal between the two MJO groups. The MJO events were not separated into seasonal groups due to the small sample size of events.

In the rest of this section, comparisons are made between the two groups of ITCZ events and between the two types of MJO initiation to address the questions raised in section 1 .

\section{b. Large-scale structures}

We first compare meridional-vertical cross sections of wind ( $v$ and $w)$ and relative humidity (RH) of the two groups of the ITCZ (Fig. 6). Their meridional-vertical circulations are almost identical: deep overturning circulation patterns are on both sides of rainfall peaks that coincide in latitude with the strongest ascending motions, with strong meridional flows in the boundary layer converging to the rainfall peak (Figs. 6a,b). Meanwhile, $\mathrm{RH}$ in the midtroposphere is significantly higher for ITCZ_M than ITCZ_NM at and south of the equator (Fig. 6c).

The evolution of the rainfall pattern during initiation of MJO_NI events has been perceived as the canonical MJO initiation before DYNAMO. Mean rainfall 

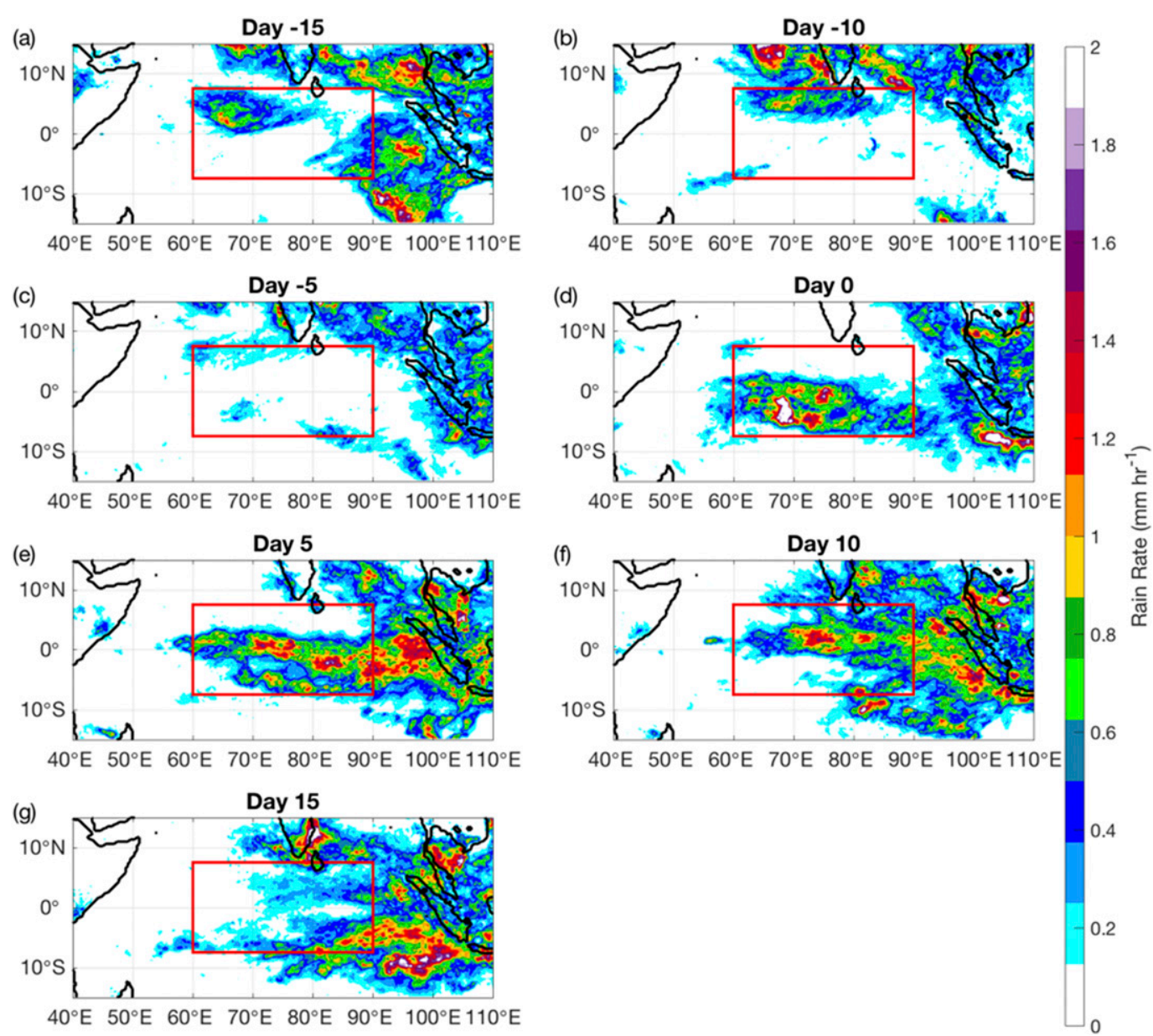

FIG. 7. Distributions of the rain rate for MJO events not immediately preceded by an ITCZ (MJO_NI) before and after their initiation days. Each panel is a 5-day average centered on the day labeled. Red box outlines the MJO analysis domain $\left(7.5^{\circ} \mathrm{S}-7.5^{\circ} \mathrm{N}, 60^{\circ}-90^{\circ} \mathrm{E}\right)$.

distributions of MJO_NI indicate that the commonly perceived convectively suppressed condition preceding MJO initiation over the Indian Ocean indeed exists but only 5 days prior to MJO initiation day on average (Fig. 7). Initiation for MJO_NI events is characterized by quick development of convection over the equatorial Indian Ocean that starts to move eastward within 5 days. The MJO typically moves east of the MJO analysis domain (red boxes, Fig. 7) within 15 days of initiation. In comparison, there is no large-scale suppressed convective condition prior to initiation of MJO_I events (Fig. 8). For this group of the MJO, convective initiation undergoes an equatorial shift and meridional expansion of an existing ITCZ starting 5 days prior to the initiation day (Fig. 8). Similar to MJO_NI, 15 days after initiation, the convection center of MJO_I has moved eastward out of the MJO analysis domain.

Figures 7 and 8 suggest that convective initiation of the MJO over the Indian Ocean takes on average
20 days to go from the pre-MJO stage (either under a convectively suppressed condition for MJO_NI or with a preexisting ITCZ for MJO_I as shown in the panels for days $-15,-10$, and -5 in Figs. 7 and 8 ) to the establishment of an eastward-moving MJO event (panels for day 0 in Figs. 7 and 8) over a broad region of the equatorial Indian Ocean. Within the MJO analysis domain, the strongest contrast in convective development during MJO initiation is between days -5 and 5 for both types of MJO initiation.

There are several interesting differences between initiation of the two types of the MJO. For MJO_I, ITCZ_M coincides with it on day -5 . Deep convergent flow (from the surface to the midtroposphere) toward the center of the ITCZ from both sides (Fig. 9a) shifts toward the equator as convection of the MJO starts to develop at day 0 (Fig. 9b) and becomes mature at day 5 (Fig. 9c). For MJO_NI, low-level cross-equatorial southerlies exist before its initiation at day -5 (Fig. 9d). It becomes 

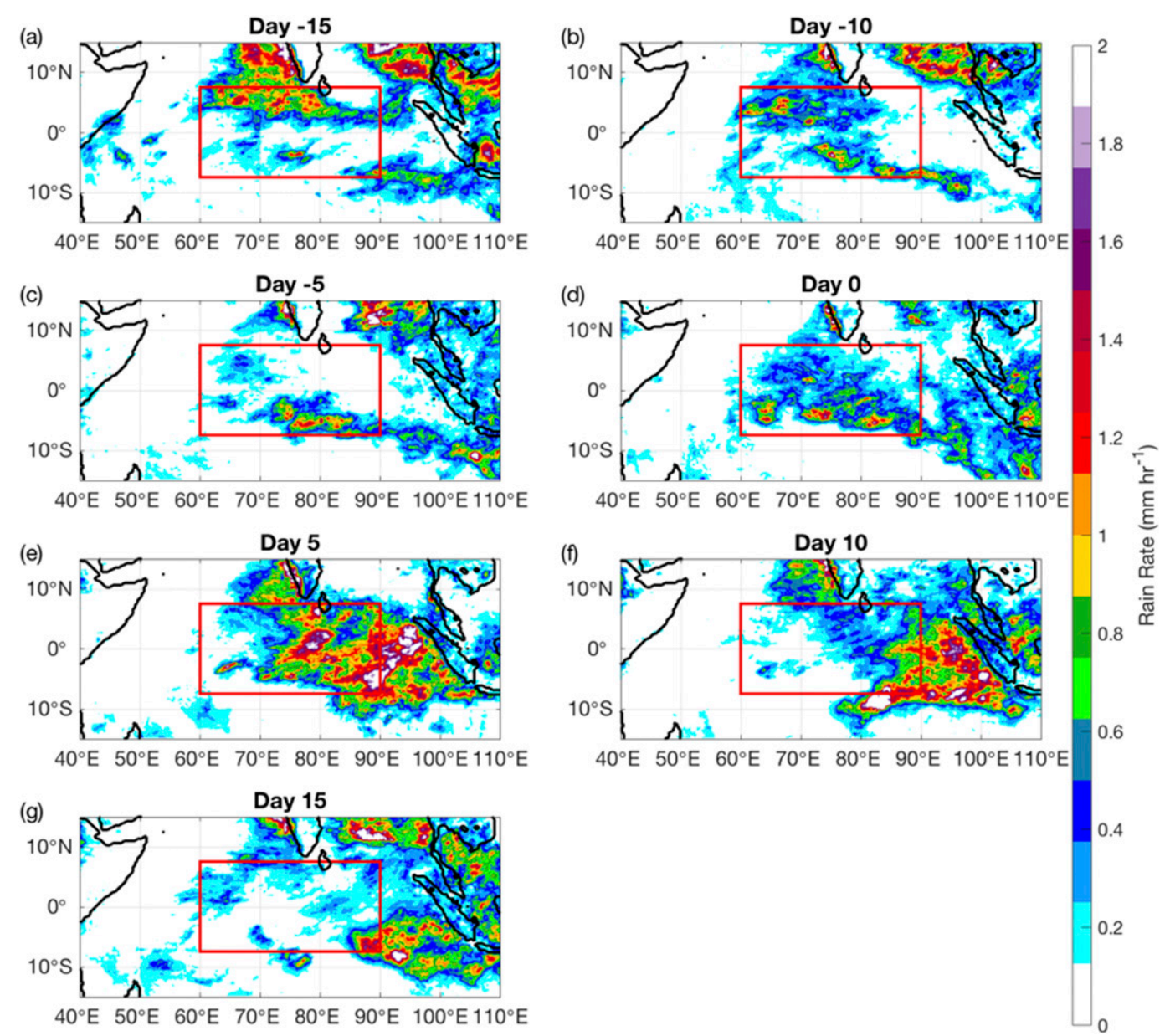

FIG. 8. As in Fig. 7, but for MJO events immediately preceded by an ITCZ (MJO_I).

stronger as MJO convection develops (Fig. 9e) and remains roughly the same from then on (Fig. 9f). But there is hardly any northerly flow in the boundary layer north of the MJO convection center; deep northerlies flows exist only above the boundary layer (Figs. 9e,f).

The deep moisture column of the ITCZ moves toward the equator and expands in latitude during convective initiation of MJO_I (Figs. 9a-c). In contrast, moistening of the midtroposphere during convective initiation of MJO_NI appears to come from below (Figs. 9d-f). This suggests upward moisture transport by moist convection. This is further emphasized by the evolution of total moisture flux convergence for both types of MJO (Fig. 10). Total moisture flux is defined as $F_{m}=-d q u / d x-d q \omega / d p$, where $q$ is specific humidity, $u$ is the zonal wind, and $\omega$ is vertical velocity in pressure coordinates. The averages from $10^{\circ} \mathrm{S}$ to $10^{\circ} \mathrm{N}$ for $q, u$, and $\omega$ are taken for the flux calculation to create the vertical cross sections. Moisture converges through the boundary layer and midtroposphere in the
ITCZ (Fig. 10a). This pattern shifts to the equator during MJO initiation (Fig. 10b). However, before initiation for MJO_NI the boundary layer exhibits the most positive moisture flux convergence near the equator (Fig. 10d). There is not a strong moisture convergence signal in the midtroposphere until MJO initiation occurs (Fig. 10e). It has been suggested that such upward moisture transport by shallow convection and congestus are essential to the development of deep convection of the MJO (Kiladis et al. 2005; Benedict and Randall 2007). Here we show that moisture in the midtroposphere associated with a preexisting ITCZ may also play an important role in the convective initiation of MJO_I. The midtroposphere is more moist for MJO_I than MJO_NI (Figs. 9h,i) because of the preexisting moist column of the ITCZ (Fig. 9g). While midtropospheric $(400-600 \mathrm{hPa})$ moisture is enhanced during the pre-initiation and initiation stage of both types of MJO, this enhancement is more gradual for MJO_NI than MJO_I (Fig. 11a). Midlevel moisture peaks on day 10 for MJO_NI, whereas for MJO_I it begins to level off 

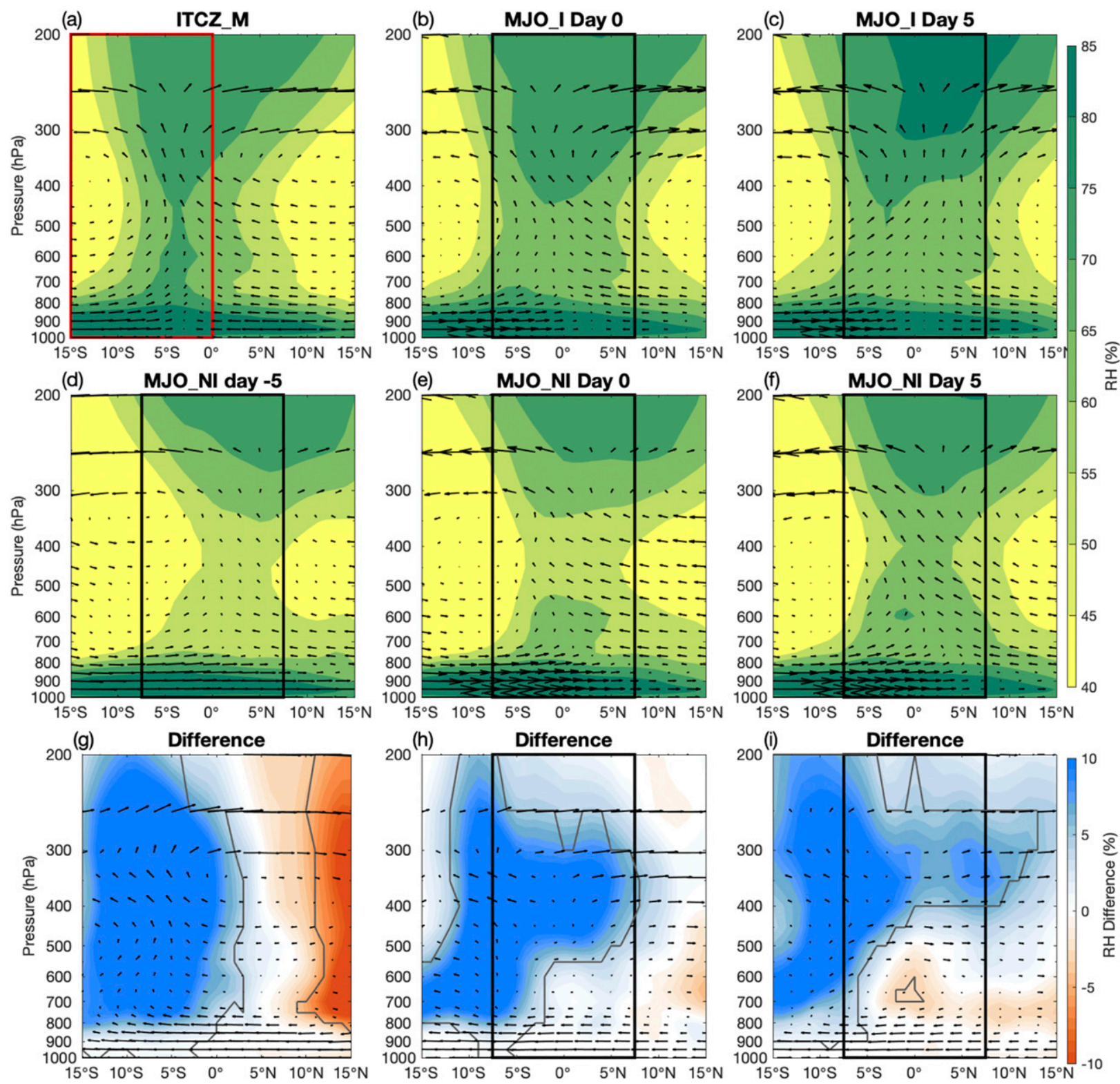

FIG. 9. As in Fig. 6, but for (a) ITCZ events immediately followed by MJO initiation (ITCZ_M); MJO events preceded by an ITCZ (MJO_I) at days (b) 0 and (c) 5; for MJO events preceded by an ITCZ (MJO_NI) at days (d) -5, (e) 0, and (f) 5; and (g) the difference between (a) and (d), (h) the difference between (b) and (e), and (i) the difference between (c) and (f). Red boxes outline the ITCZ domain $\left(0^{\circ}-15^{\circ} \mathrm{S}, 60^{\circ}-90^{\circ} \mathrm{E}\right)$, and black boxes outline the MJO domain $\left(7.5^{\circ} \mathrm{S}-7.5^{\circ} \mathrm{N}, 60^{\circ}-90^{\circ} \mathrm{E}\right)$.

at initiation and peaks at day 5 before beginning a gradual decline.

\section{c. Precipitation features}

The convective characteristics are compared in terms of several parameters of the PFs in the MJO and ITCZ domains, respectively, for all PFs, stratiform and convective components, and their small $\left(<1000 \mathrm{~km}^{2}\right)$ and large $\left(>1000 \mathrm{~km}^{2}\right)$ populations. No significant difference in these PFs is found between ITCZ_M and ITCZ_NM.
Hereafter, we shall discuss possible differences in convective characteristics in terms of the PFs during initiation of MJO_I and MJO_NI.

As expected from previous studies (Barnes and Houze 2013; Xu et al. 2015; Xu and Rutledge 2014), PF areal coverage increases from pre-initiation days (day -5$)$ toward the initiation day (day 0) and reaches its peak after initiation at day 5 for both groups of the MJO (Fig. 11b). This is mainly contributed by the large $\left(>1000 \mathrm{~km}^{2}\right)$ stratiform component of PFs. Dividing 

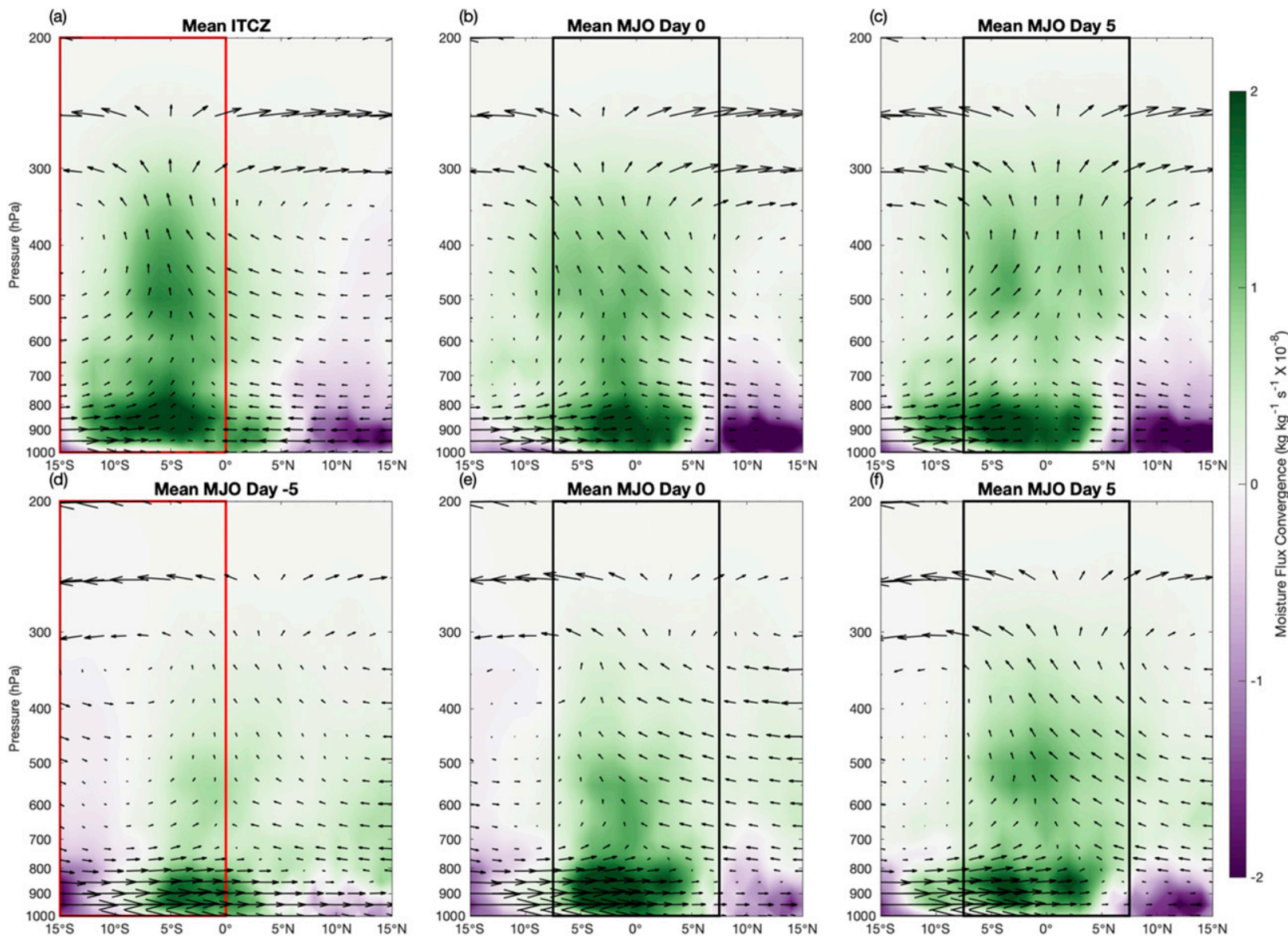

FIG. 10. As in Figs. 9a-f, but total moisture flux convergence in the color contours. Green indicates an influx of moisture, and purple indicates an outflow of moisture.

the convective area of PFs by the stratiform area (Fig. 12a) or dividing the convective volumetric rain by the stratiform volumetric rain (Fig. 12b) reveals many similarities between the two groups of MJO. The convective-stratiform ratio of $\mathrm{PF}$ area is most similar between total PF and large PF for both MJO_I and MJO_NI (Fig. 12a). The small convective-stratiform ratio for total $\mathrm{PF}$ and large $\mathrm{PF}$ indicates the areal coverage is dominated by stratiform clouds. The percentage of areal coverage by the convective component of $\mathrm{PFs}$ does not change much during MJO initiation. The main difference between the two types of MJO initiation is that the increase in the total and large stratiform component of PFs is gradual for MJO_I while it occurs faster after the initiation day for MJO_NI. This is demonstrated when the number of large PF is divided by the number of small PF. The large versus small PF ratio is much greater for MJO_I than MJO_NI from day -15 through day 5 for total and stratiform of PFs (Fig. 12c). This indicates that MJO_I has a larger proportion of large stratiform PF compared to MJO_NI during the pre-initiation phase. The large versus small ratio for MJO_NI catches up with MJO_I at day 5 after a quick increase following MJO initiation. This ratio is also greater for convective parts of PF but the difference between MJO_I and MJO_NI is not as big as for the total PF or the stratiform part of PFs. This might be related to the existing moist column of the ITCZ that moves toward the equator (Fig. 9) and continuously supports the formation of large stratiform PFs for MJO_I, whereas for MJO_NI PFs must rely on the convective moistening process that does not exist prior to its initiation.

Associated with this evolution in PF areal coverage is a quick increase in total volumetric rain over the MJO domain for MJO_NI; this increase occurs earlier and then becomes subtler for MJO_I in comparison to MJO_NI (Fig. 11c). Rainfall from large PFs $\left(>1000 \mathrm{~km}^{2}\right)$ is the main factor for this difference between the two types of MJO initiation. MJO_I has a higher fraction of volumetric rain originating from large PFs than MJO_NI during pre-MJO initiation through 

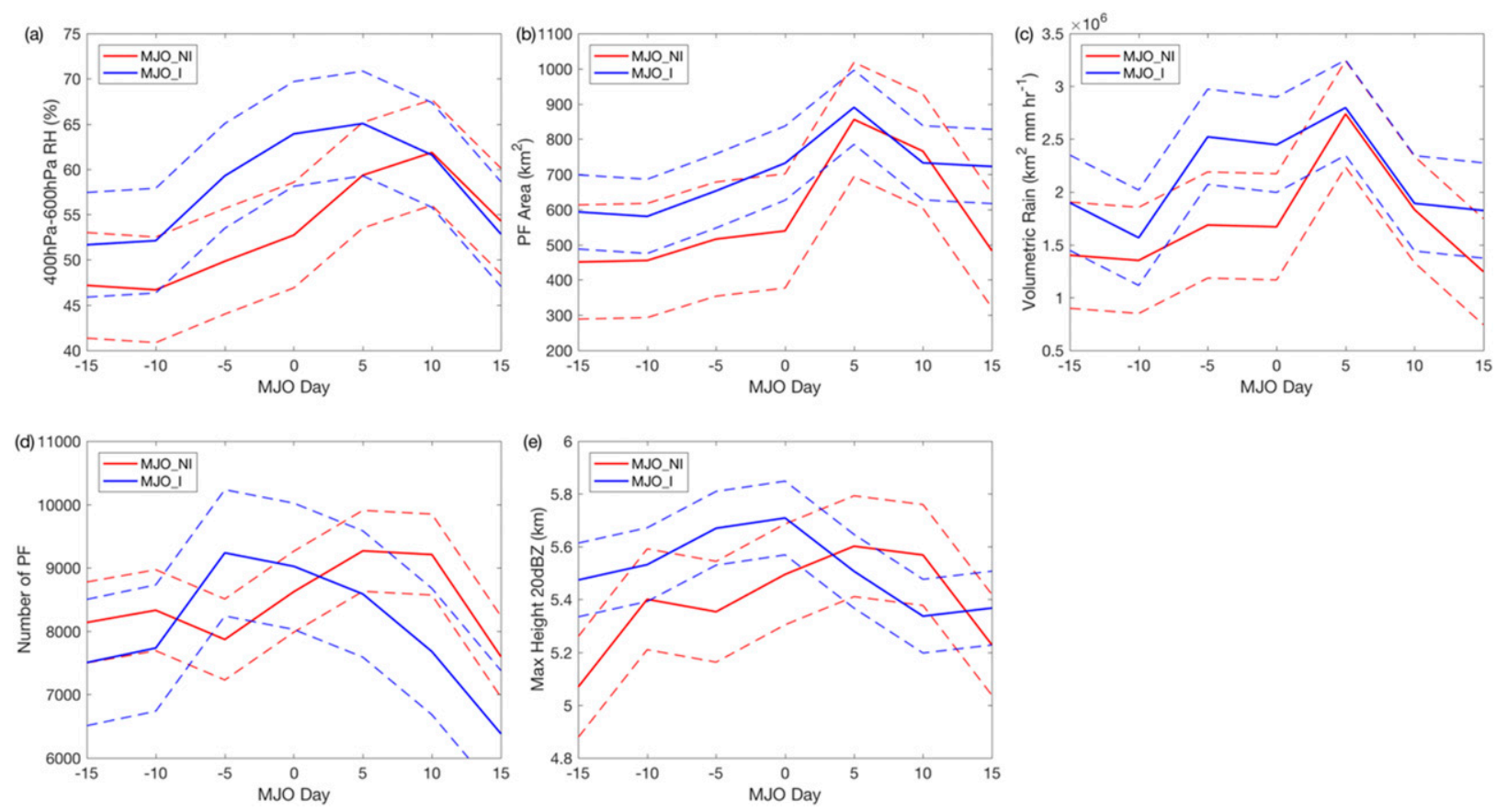

FIG. 11. Time series of domain-averaged (solid) (a) 400-600-hPa relative humidity, (b) area covered by all PFs, (c) volumetric rain, (d) total PF numbers for all MJO events, and (e) average maximum height of $20-\mathrm{dBZ}$ level of PFs in the MJO domain $\left(7.5^{\circ} \mathrm{S}-7.5^{\circ} \mathrm{N}\right.$, $60^{\circ}-90^{\circ} \mathrm{E}$ ) for MJO events immediately preceded by an ITCZ (MJO_I; blue) and MJO events not immediately preceded by an ITCZ (MJO_NI; red) and plus and minus one standard deviation (dashed).

day 5 (Fig. 12d). This suggests that large PFs, which have a high proportion of stratiform rain (Fig. 12b), quickly develop during the convective initiation of MJO_NI, whereas they already exist in the preceding ITCZ for initiation of MJO_I.

There is a positive relationship between midlevel (400-600 hPa) moisture and daily stratiform volumetric rain values (Figs. 13a,b). They are significantly correlated (at the $95 \%$ confidence level) for all days from 1998 to 2013 (with the degree of the freedom being 40, the total number of MJO events) as well as for 24 MJO_I and MJO_NI events combined (day -15 to day 15 , with the degrees of freedom being 24). Total and convective volumetric rain values are also positively correlated with midlevel moisture (Figs. 13c-f). Higher values of midlevel moisture are not the only driving force controlling the amount of volumetric rain, but it provides a favorable condition for higher values of volumetric rain. The average area of PFs in the MJO domain is also correlated with midlevel moisture at the significance level of $95 \%$ (not shown). The maximum height of the $20-\mathrm{dB} Z$ level and the number of PFs in the MJO domain do not have significant correlation with midlevel moisture (not shown). These simple statistics suggest the different behaviors of PFs associated with MJO_I and MJO_NI are at least partially related to midtropospheric moisture, which in turn is related to the presence or absence of a preexisting ITCZ.

There is also a difference in the evolution of total number of PFs between the two types of MJO initiation. This number reaches its peak before convective initiation of MJO_I at day -5 and decreases afterward, whereas its peak is not reached until after the initiation of MJO_NI at day 5 (Fig. 11d). This phase difference in the total number of PFs is a consequence of existing convection in the ITCZ, both small and large convective and stratiform PF areas, before convective initiation of MJO_I and their absence before convective initiation of MJO_NI, for which the increasing number of PFs is mainly from large, stratiform area of PFs (Fig. 12c).

The convection height, defined as the maximum height of PFs (measured by $20-\mathrm{dB} Z$ echo tops), varies in concert with the total PF numbers. It continuously increases from day -5 through day 5 for MJO_NI, but for MJO_I it plateaus at days -5 and 0 because of existing tall convection in the ITCZ and starts decreasing after day 0 (Fig. 11e). These different phases in convection height between the two types of MJO initiation is mainly due to small $\left(<1000 \mathrm{~km}^{2}\right)$ PFs (not shown). This implies that a preexisting ITCZ (day -5 ) helps deep convective growth leading to MJO initiation (day 0), whereas the growth of deep convection happens 

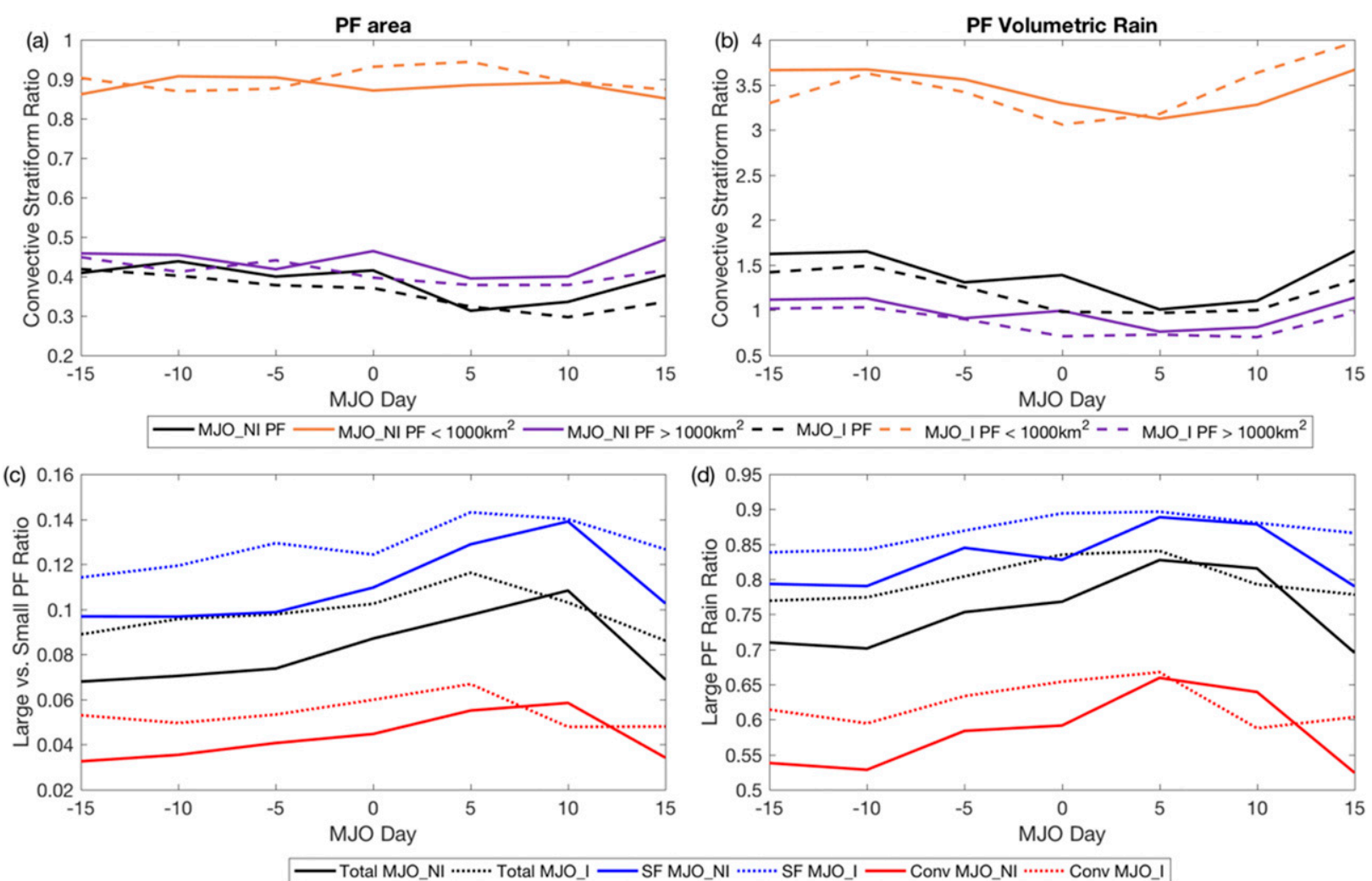

FIG. 12. Time series of convective-stratiform ratio for PF (a) area and (b) volumetric rain, where black is all size PFs, orange is small PFs $\left(<1000 \mathrm{~km}^{2}\right)$, and purple is large PFs $\left(>1000 \mathrm{~km}^{2}\right)$. (c) Time series of large vs small PF ratio (number of PFs $>1000 \mathrm{~km}{ }^{2}$ divided by number of PFs $<1000 \mathrm{~km}^{2}$ ), where black is all PFs, blue is stratiform part of PFs, and red is convective part of PFs. (d) Time series of the fraction of total volumetric rain from large PFs (volumetric rain from PFs $>1000 \mathrm{~km}^{2}$ divided by volumetric rain from all PFs), where black is all PFs, blue is stratiform part of PFs, and red is convective part of PFs.

at a later stage (after day 0) for MJO without a preceding ITCZ

\section{d. DYNAMO cases}

This study was motivated by the observations during the DYNAMO field campaign that convective initiation of the MJO over the Indian Ocean did not start from a large-scale convectively suppressed condition over the Indian Ocean as previously perceived but from a condition with active convection in a form of the ITCZ (Johnson and Ciesielski 2013; Yoneyama et al. 2013; Kerns and Chen 2014; Ciesielski et al. 2018). The initiation dates (day 0) of MJO1 and MJO2 according to the Ling et al. (2014) MJO tracking method were 20 October and 15 November 2011, respectively. The precipitation patterns of MJO1 at days 10 and 15 (Figs. 14f,g) are roughly the same as those of MJO2 at days -15 and -10 (Figs. 15a,b) because one event followed the other. Neither case was included in the composites shown in the previous subsections because they did not meet the strict criteria for MJO_I. However, a comparison of $\mathrm{MJO}$ events observed during the field campaign to our results presented here could provide more information about modes of MJO initiation.

MJO1 had a preexisting ITCZ, as defined by our method. The evolution of MJO1 precipitation clearly shows the ITCZ pattern at day -10 (Fig. 14b), which then expanded toward the equator at day -5 , covered almost the entire MJO domain at days 0 and 5 (Figs. 14d,e), and moved east during days 10-15 (Figs. 14f,g). The large-scale humidity field shows two moist columns at day -5 (Fig. 16a), one associated with the near-equator expanded ITCZ and the other with a rainband to the north (Fig. 14c). The moist columns merged into a single broad column at day 0 (Fig. 16b), which expanded northward later (Fig. 16c). The corresponding circulation is like that of MJO_NI, with southerly flows in the boundary layer across the entire MJO domain. The area and volumetric rain of PFs both peak on day 10 (Figs. 17a,b). The number of PFs steadily increases until initiation and begins a steady decrease similarly to the behavior of MJO_I (Fig. 17c). The height of the PFs also increase up to initiation and plateaus as seen in MJO_I (Fig. 17d). 
(a)

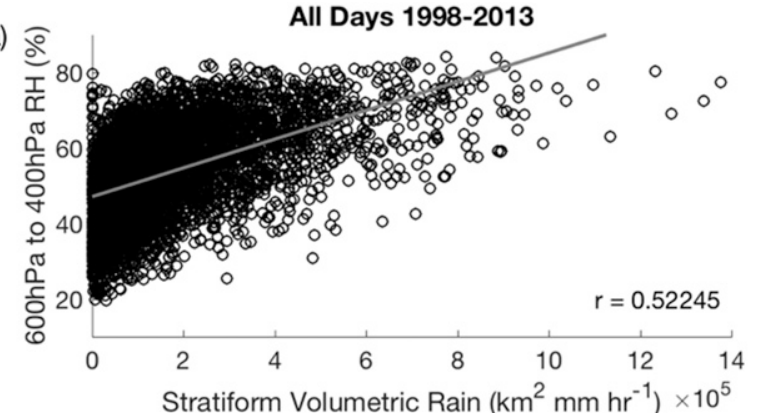

(c)

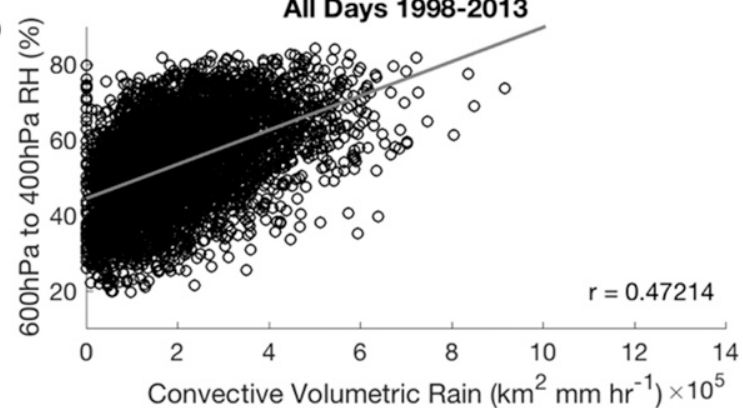

(e)

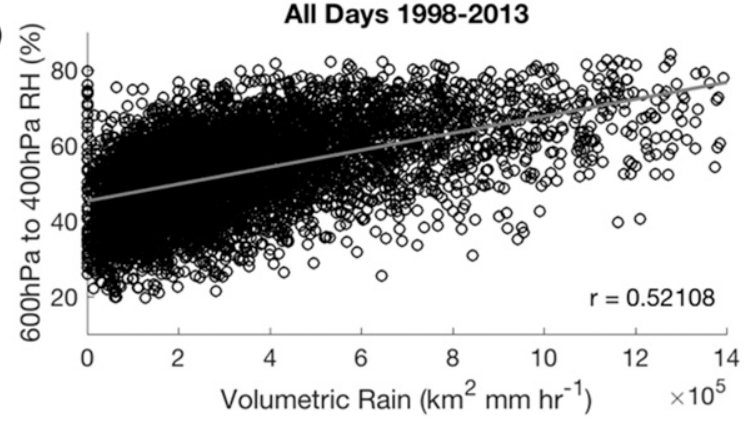

(b)

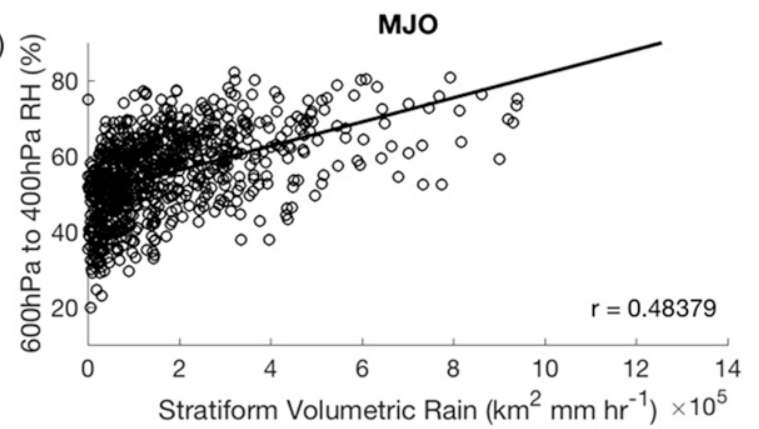

(d)

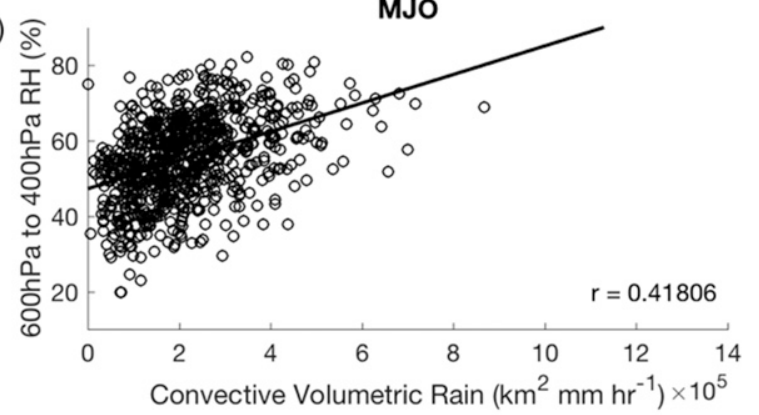

MJO

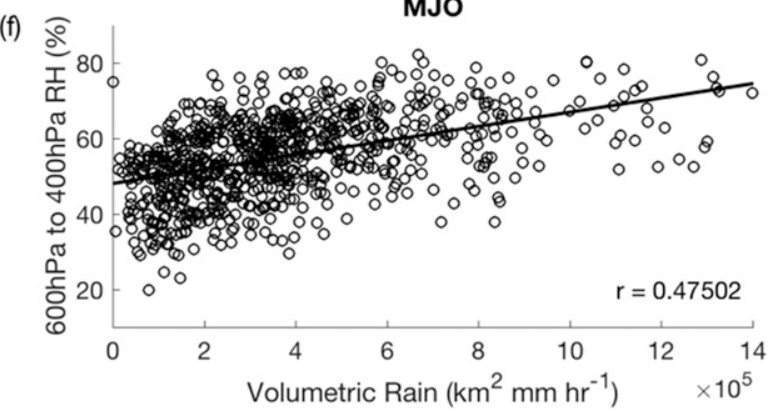

FIG. 13. (top) Scatterplots of domain-average PF stratiform volumetric rain vs average 600-400-hPa RH in the MJO domain for (a) all days and (b) days associate with MJO_I and MJO_NI. (middle) Scatterplots of domain-average PF convective volumetric rain vs average 600-400-hPa RH in the MJO domain for (c) all days and (d) days associate with MJO_I and MJO_NI. (bottom) Scatterplots of domain-average $\mathrm{PF}$ total volumetric rain vs average $600-400-\mathrm{hPa} \mathrm{RH}$ in the MJO domain for (e) all days and (f) days associated with MJO_I and MJO_NI.

Despite the discrepancy in the low-level circulation pattern, the parallels in large-scale moisture and $\mathrm{PF}$ behavior between MJO_I and MJO1 indicate the preexisting ITCZ provided a source of moisture for MJO1 initiation.

$\mathrm{MJO} 2$ initiated over the African continent $\left(36.6^{\circ} \mathrm{E}\right)$ according the Ling et al. (2014) tracking method. $\mathrm{MJO} 2$ initiation may be related to fast circumnavigating upper-level waves triggered by MJO1 (Gottschalck et al. 2013; Yoneyama et al. 2013; Powell and Houze 2015). Before MJO convection reached the Indian Ocean, there was preexisting ITCZ convection (Figs. 15b-d). The large-scale circulation pattern is very similar to that of MJO_I, with deep convergent flows at both south and north sides from the boundary layer to the midtroposphere (Figs. 15d,e) before and during its initiation, suggesting the ITCZ provided a source of moisture for this event. On the other hand, moistening appears to start from the bottom up, suggesting upward transport of moisture as seen in MJO_NI (Figs. 9d-f). The PF area and volumetric rain peaks on day 10 (Figs. 17a,b). The number of PF and maximum height of PFs peaks on day 5 (Figs. 16c,d). Unlike MJO1 and MJO_I, the height of PFs quickly increases before the peak and quickly decreases after the peak.

Although these DYNAMO MJO cases were not selected as MJO_I nor MJO_NI, their similarities and differences in comparison to MJO_I and MJO_NI suggest a wide variety of scenarios of MJO initiation. It has been previously shown that the suppressed phases of MJO1 and MJO2 had marginally negative 

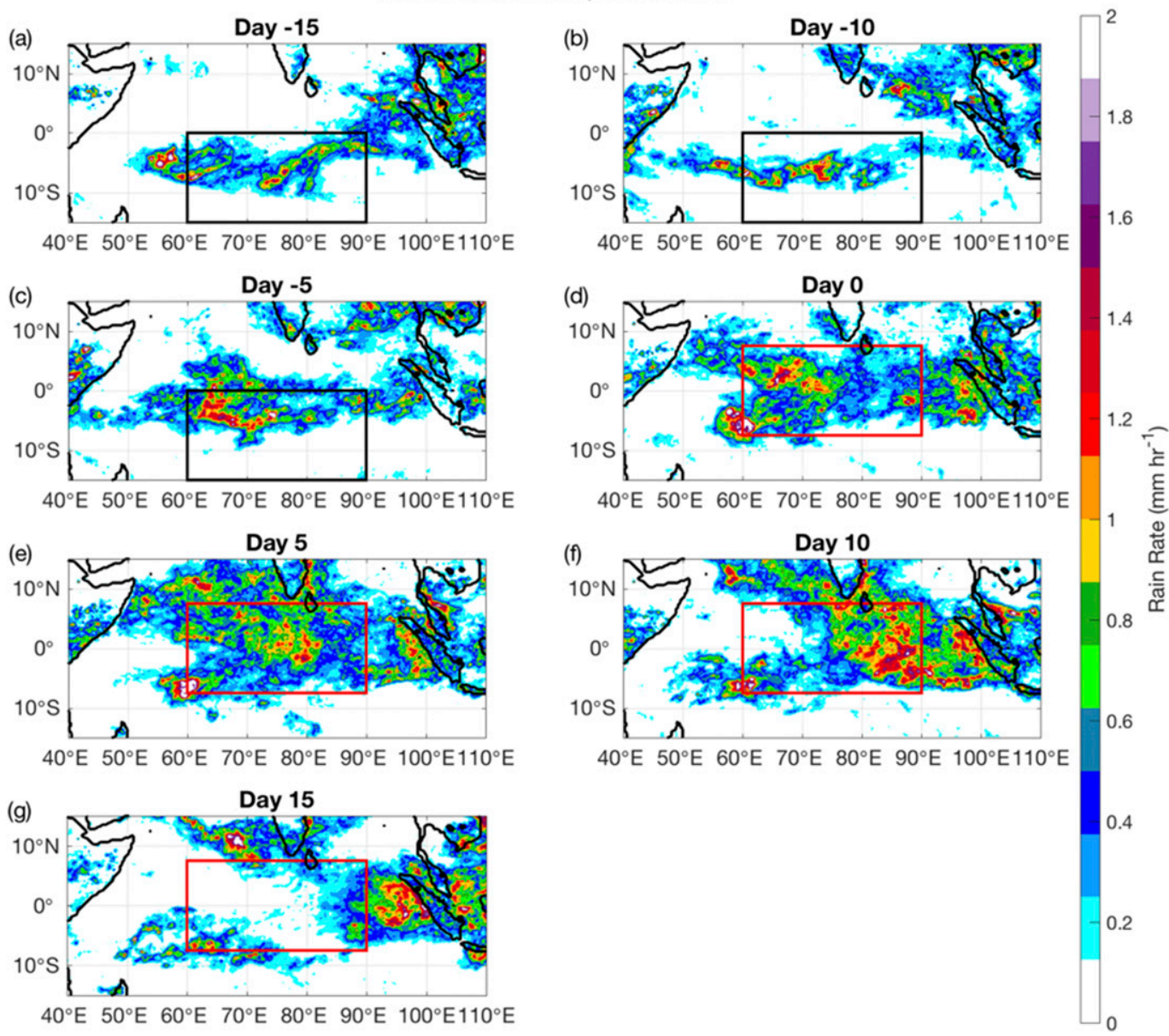

FIG. 14. As in Fig. 7, but for MJO1.

moisture anomalies near the surface (Gottschalck et al. 2013). In other words, the suppressed period was slightly more moist than usual. Radar observations of ITCZ convection taken near $8^{\circ} \mathrm{S}$ during DYNAMO found a steady moistening of the environment before MJO initiation by a large population of scattered shallow convective systems (Rowe and Houze 2015; $\mathrm{Xu}$ et al. 2015). RH under $800 \mathrm{hPa}$ for both MJO1 and MJO2 reflect this with reasonable high values (Figs. 16a-d). This coincides with the presence of the ITCZ convection occurring during the suppressed phase for both events (Figs. 12a-c, 15b, and 15c), suggesting the ITCZ provided a moisture source to aid in convective initiation of the MJO over the Indian Ocean.

\section{Summary and discussion}

The objective of this study was to investigate the extent to which the ITCZ could play a role in MJO initiation. We compared convective initiation of the
MJO with a preceding ITCZ (MJO_I) and without (MJO_NI) to seek evidence of such a role of the ITCZ. A set of criteria was developed to objectively identify ITCZ convection over the Indian Ocean. MJO events were identified by a method that tracks eastward moving rainfall anomalies, as described in Ling et al. (2014) and Zhang and Ling (2017).

An ITCZ is neither a necessary nor sufficient condition for convective initiation of the MJO. Of all identified convective initiation of the MJO events over the Indian Ocean, roughly 30\% immediately follow an existing ITCZ without any gap. Another $30 \%$ follow an ITCZ with gaps from 1 to 10 days. The rest are not related to any ITCZ. Convective initiation of the MJO over the Indian Ocean exhibits different characteristics in both the large-scale circulation and precipitation features with and without an immediately preceding ITCZ.

Differences in the large-scale environment of MJO_I and MJO_NI events suggest different processes of 

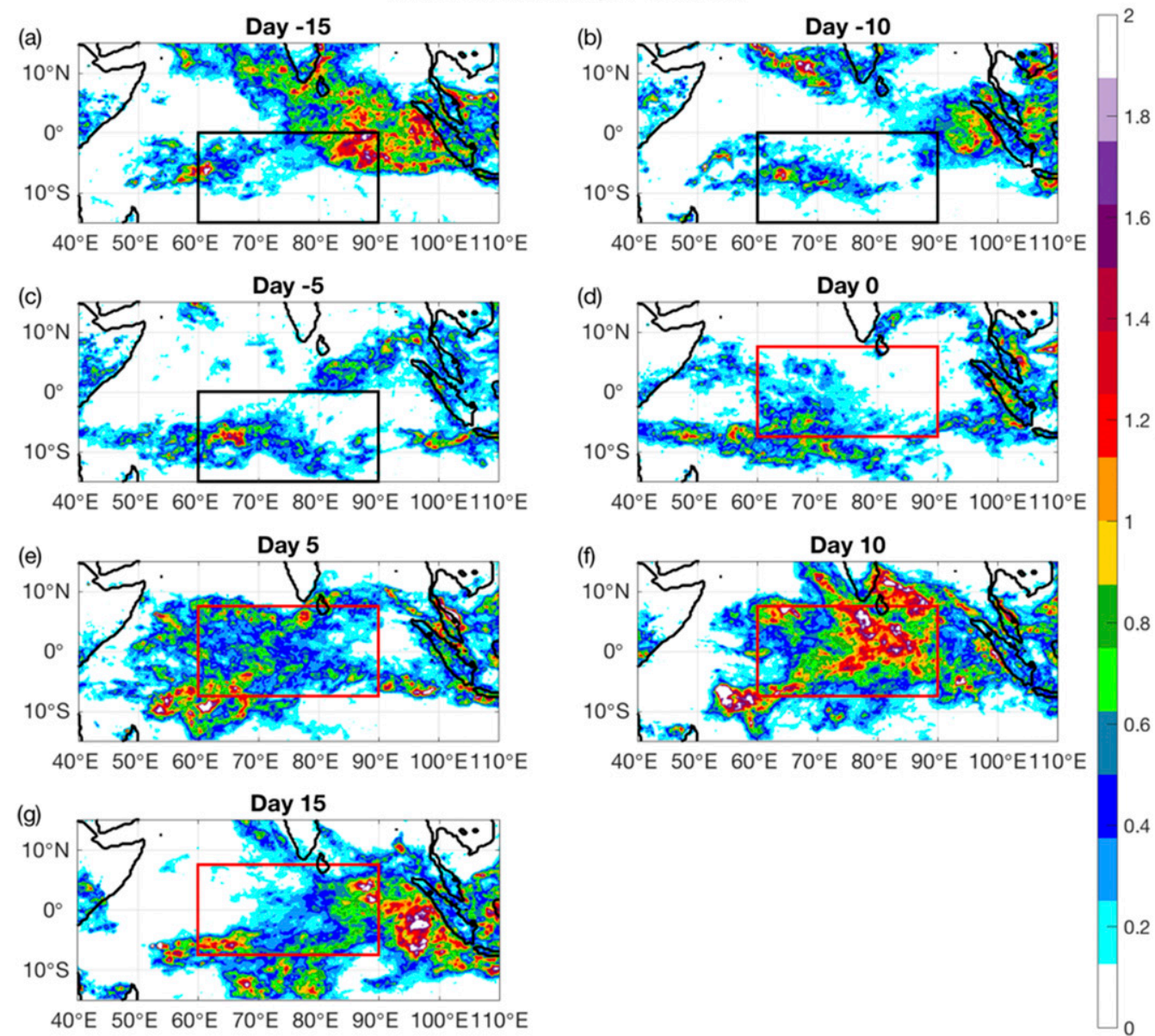

FIG. 15. As in Fig. 7, but for MJO2.

convective initiation of the MJO. Low- and midlevel moistening before MJO initiation has been documented by many studies (Wang and Rui 1990; Stephens et al. 2004; Benedict and Randall 2007; Lau and Wu 2010; Del Genio et al. 2012) and it was suggested to be essential to the simulation of the MJO (Zhang and Song 2009; Del Genio et al. 2012). During convective initiation of MJO_I, low- and midlevel moisture already exists because of the ITCZ. For MJO_NI, different mechanisms (e.g., vertical moisture transport by shallow and congestus convection) are needed to supply low- and midlevel moisture.

Radar observations taken south of the equator near $8^{\circ} \mathrm{S}$ during DYNAMO found a large population of scattered shallow convective systems and a steady moistening of the environment due to ITCZ convection before MJO initiation (Rowe and Houze 2015; $\mathrm{Xu}$ et al. 2015). This active convection in the ITCZ was found to cause large-scale subsidence at the equator during DYNAMO (Yoneyama et al. 2013;
Johnson and Ciesielski 2013; Kerns and Chen 2014). In our composite of the large-scale circulation around the ITCZ (Fig. 6), there is no subsidence within $10^{\circ}$ from the ITCZ center, suggesting that equatorial subsidence in the presence of a Southern Hemispheric ITCZ can be observed on a case by case basis but is not a prominent climatological feature possibly because of the fluctuations in the width, strength, and latitudinal location of the ITCZ.

Increases in the total areal coverage and number of precipitating systems, the amount of rainfall, and the maximum height of convective systems are evidence of the convective evolution during initiation of both MJO_I and MJO_NI. These characteristics have been commonly observed from satellites (Morita et al. 2006) and radars (Barnes and Houze 2013; Xu and Rutledge 2014; Xu et al. 2015). Subtle differences exist between the evolution of convection during initiation of MJO_I and MJO_NI. These differences include abrupt versus gradual increases in PF areal coverage and volumetric 

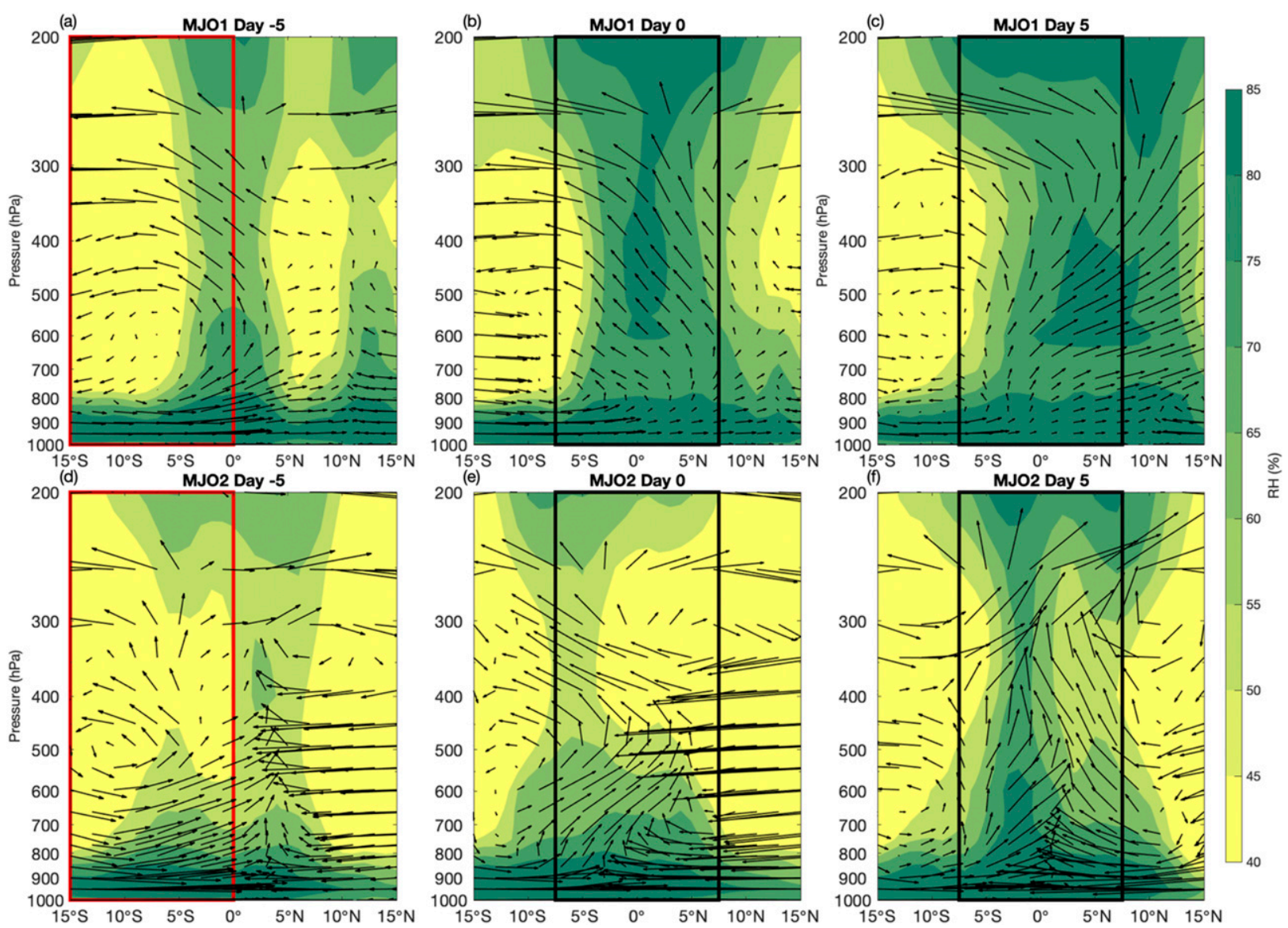

FIG. 16. As in Fig. 6, but for (top) MJO1 at days (a) -5, (b) 0, and (c) 5 and (bottom) MJO2 at days (d) -5 , (e) 0, and (f) 5. Red boxes outline the ITCZ domain, and black boxes outline the MJO domain.

rain and a slight shift of phases in the number of $\mathrm{PF}$ and their maximum height (Fig. 11). The differences are related to the large-scale moist environment in the presence of an ITCZ and dry environment in the absence of an ITCZ immediately prior to convective initiation of the $\mathrm{MJO}$, as suggested by their correlation with midtropospheric moisture (Fig. 13). These results illustrate how a preceding ITCZ may help convective development during MJO initiation to occur earlier and more gradually than that for MJO initiation without a preceding ITCZ. It is unclear whether this assistance from a preceding ITCZ would cause MJO initiation to happen easier, meaning requiring less strenuous largescale conditions, whatever they might be. If so, then it is natural to ask whether the frequency or total number of MJO initiation over the Indian Ocean would be lower if there was no ITCZ and whether the ITCZ is a reason for the fact that most MJO initiation occurs over the Indian Ocean (Zhang and Ling 2017).

The results from this study provide observational evidence of different scenarios of convective initiation of the
MJO. They encourage an approach to the study of MJO initiation different from those that have been practiced. The traditional view of MJO initiation as a process of convective development starting from a suppressed period or one of shallow to deep convective transition (Madden and Julian 1972) is still valid but incomplete. We need to explore MJO initiation as a multifaceted process that includes, in addition to the traditionally perceived convective development, convective transformation from the ITCZ to MJO in both large-scale environment and distributions of convective systems. More detailed and comprehensive data analyses are needed to establish a knowledge base for advanced understanding and realistic numerical simulations of MJO initiation. The differences in midtropospheric humidity and moisture flux convergence observed in this study needs to be quantified through a detailed water vapor budget analysis. The multifaceted processes of MJO initiation may suggest, however, that these processes might not be essential to MJO initiation if each of them is neither necessary nor sufficient for MJO initiation. If this is the case, a more 

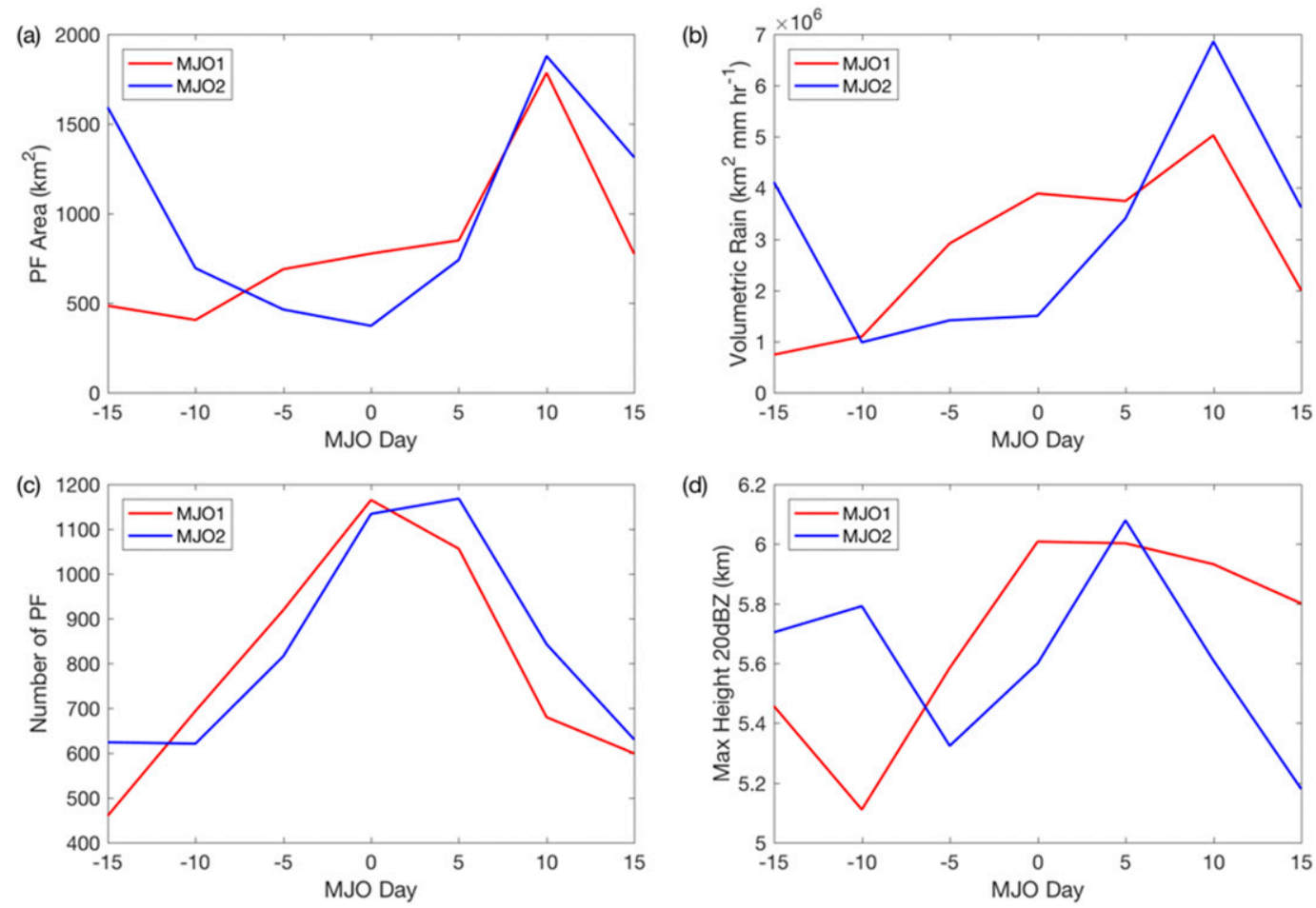

FIG. 17. Time series of (a) average area covered by all PFs, (b) average domain volumetric rain, (c) total number of PFs, and (d) average maximum height for $20 \mathrm{dBZ}$ in the MJO domain for MJO1 (red) and MJO2 (blue).

fundamental understanding is required to identify the core process of MJO initiation.

Acknowledgments. The authors thank Paul Ciesielski for encouragement and discussions during the writing of this manuscript and anonymous reviewers for their constructive comments on its early versions. This study was supported by NSF Grant AGS-1450582 and NOAA Grant NA13OAR310161. This is PMEL contribution 4878.

\section{REFERENCES}

Adames, Á. F., and D. Kim, 2016: The MJO as a dispersive, convectively coupled moisture wave: Theory and observations. J. Atmos. Sci., 73, 913-941, https://doi.org/10.1175/ JAS-D-15-0170.1.

Ashok, K., Z. Guan, and T. Yamagata, 2001: Impact of the Indian Ocean dipole on the relationship between the Indian monsoon rainfall and ENSO. Geophys. Res. Lett., 28, 4499-4502, https:// doi.org/10.1029/2001GL013294.

,$- \ldots$, N. H. Saji, and T. Yamagata, 2004: Individual and combined influences of ENSO and the Indian Ocean dipole on the Indian summer monsoon. J. Climate, 17, 3141-3155, https://doi.org/10.1175/1520-0442(2004)017<3141:IACIOE > 2.0.CO;2.

Awaka, J., T. Iguchi, and K. Okamoto, 1998: Early results on rain type classification by the Tropical Rainfall Measuring Mission (TRMM) precipitation radar. Proc. 8th URSI Commission Final Open Symp., Aveiro, Portugal, URSI, 143-146.
Bain, C. L., J. De Paz, J. Kramer, G. Magnusdottir, P. Smyth, H. Stern, and C.-C. Wang, 2011: Detecting the ITCZ in instantaneous satellite data using spatiotemporal statistical modeling: ITCZ climatology in the east Pacific. J. Climate, 24, 216-230, https://doi.org/10.1175/2010JCLI3716.1.

Barnes, H. C., and R. A. Houze, 2013: The precipitating cloud population of the Madden-Julian Oscillation over the Indian and west Pacific Oceans. J. Geophys. Res. Atmos., 118, 69967023, https://doi.org/10.1002/jgrd.50375.

Benedict, J. J., and D. a. Randall, 2007: Observed characteristics of the MJO relative to maximum rainfall. J. Atmos. Sci., 64, 2332-2354, https://doi.org/10.1175/JAS3968.1.

Biello, J. A., and A. J. Majda, 2005: A new multiscale model for the Madden-Julian oscillation. J. Atmos. Sci., 62, 1694-1721, https://doi.org/10.1175/JAS3455.1.

Ciesielski, P. E., R. H. Johnson, and W. E. Schubert, 2018: Diurnal cycle of the ITCZ in DYNAMO. J. Climate, 31, 4543-4562, https://doi.org/10.1175/JCLI-D-17-0670.1.

Dee, D. P., and Coauthors, 2011: The ERA-Interim reanalysis: Configuration and performance of the data assimilation system. Quart. J. Roy. Meteor. Soc., 137, 553-597, https:// doi.org/10.1002/qj.828.

Del Genio, A. D., Y. Chen, D. Kim, and M.-S. Yao, 2012: The MJO transition from shallow to deep convection in CloudSat/CALIPSO Data and GISS GCM simulations. J. Climate, 25, 3755-3769, https://doi.org/10.1175/JCLI-D11-00384.1.

Fuchs, Z., and D. J. Raymond, 2017: A simple model of intraseasonal oscillations. J. Adv. Model. Earth Syst., 9, 11951211, https://doi.org/10.1002/2017MS000963.

Gottschalck, J., P. E. Roundy, C. J. Schreck III, A. Vintzileos, and C. Zhang, 2013: Large-scale atmospheric and oceanic 
conditions during the 2011-12 DYNAMO field campaign. Mon. Wea. Rev., 141, 4173-4196, https://doi.org/10.1175/ MWR-D-13-00022.1.

Haffke, C., G. Magnusdottir, D. Henke, P. Smyth, and Y. Peings, 2016: Daily states of the March-April east Pacific ITCZ in three decades of high-resolution satellite data. J. Climate, 29, 2981-2995, https://doi.org/10.1175/JCLI-D-15-0224.1.

Houze, R. A., K. L. Rasmussen, M. D. Zuluaga, and S. R. Brodzik, 2015: The variable nature of convection in the tropics and subtropics: A legacy of 16 years of the Tropical Rainfall Measuring Mission satellite. Rev. Geophys., 53, 994-1021, https://doi.org/10.1002/2015RG000488.

Hsu, H., B. Hoskins, and F.-F. Jin, 1990: The 1985/86 intraseasonal oscillation and the role of the extratropics. J. Atmos. Sci., 47, 823-839, https://doi.org/10.1175/1520-0469(1990)047<0823: TIOATR $>2.0 . \mathrm{CO} ; 2$.

Huffman, G. J., and D. T. Bolvin, 2014: TRMM and other data precipitation data set documentation. NASA TRMM Doc., 42 pp. ftp://precip.gsfc.nasa.gov/pub/trmmdocs/3B42_3B43_doc.pdf.

Hung, M. P., J. L. Lin, W. Wang, D. Kim, T. Shinoda, and S. J. Weaver, 2013: MJO and convectively coupled equatorial waves simulated by CMIP5 climate models. J. Climate, 26, 61856214, https://doi.org/10.1175/JCLI-D-12-00541.1.

Jiang, X., and Coauthors, 2015: Vertical structure and physical processes of the Madden-Julian oscillation: Exploring key model physics in climate simulations. J. Geophys. Res. Atmos., 120, 4718-4748, https://doi.org/10.1002/2014JD022374.

Johnson, R. H., and P. E. Ciesielski, 2013: Structure and properties of Madden-Julian oscillations deduced from DYNAMO sounding arrays. J. Atmos. Sci., 70, 3157-3179, https://doi.org/ 10.1175/JAS-D-13-065.1.

Kemball-Cook, S. R., and B. C. Weare, 2001: The onset of convection in the Madden-Julian oscillation. J. Climate, $\mathbf{1 4}$ 780-793, https://doi.org/10.1175/1520-0442(2001)014<0780: TOOCIT $>2.0 . \mathrm{CO} ; 2$.

Kerns, B. W., and S. S. Chen, 2014: Equatorial dry air intrusion and related synoptic variability in MJO initiation during DYNAMO. Mon. Wea. Rev., 142, 1326-1343, https://doi.org/10.1175/MWRD-13-00159.1.

Kiladis, G. N., K. H. Straub, and P. T. Haertel, 2005: Zonal and vertical structure of the Madden-Julian oscillation. J. Atmos. Sci., 62, 2790-2809, https://doi.org/10.1175/JAS3520.1.

Lau, K.-M., and H.-T. Wu, 2010: Characteristics of precipitation, cloud, and latent heating associated with the Madden-Julian oscillation. J. Climate, 23, 504-518, https://doi.org/10.1175/ 2009JCLI2920.1.

Lin, H., G. Brunet, and J. Derome, 2007: Intraseasonal variability in a dry atmospheric model. J. Atmos. Sci., 64, 2422-2441, https://doi.org/10.1175/JAS3955.1.

Ling, J., C. Zhang, and P. Bechtold, 2013: Large-scale distinctions between MJO and Non-MJO convective initiation over the tropical Indian Ocean. J. Atmos. Sci., 70, 2696-2712, https:// doi.org/10.1175/JAS-D-13-029.1.

—, P. Bauer, P. Bechtold, A. Beljaars, R. Forbes, F. Vitart, M. Ulate, and C. Zhang, 2014: Global versus local MJO forecast skill of the ECMWF model during DYNAMO. Mon. Wea. Rev., 142, 2228-2247, https://doi.org/10.1175/MWR-D-13-00292.1.

Liu, C., and E. Zipser, 2013: Regional variation of morphology of organized convection in the tropics and subtropics. J. Geophys. Res. Atmos., 118, 453-466, https://doi.org/10.1029/ 2012JD018409.

_ E. J. Zipser, D. J. Cecil, S. W. Nesbitt, and S. Sherwood, 2008: A cloud and precipitation feature database from nine years of
TRMM observations. J. Appl. Meteor. Climatol., 47, 27122728, https://doi.org/10.1175/2008JAMC1890.1.

Madden, R. A., and P. R. Julian, 1971: Detection of a 40-50 day oscillation in the zonal wind in the tropical Pacific. J. Atmos. Sci., 28, 702-708, https://doi.org/10.1175/1520-0469(1971)028<0702: DOADOI $>2.0$.CO;2.

$\longrightarrow$, and - 1972: Description of global-scale circulation cells in the tropics with a 40-50 day period. J. Atmos. Sci., 29, 1109-1123, https://doi.org/10.1175/1520-0469(1972)029<1109:DOGSCC> 2.0.CO;2.

Majda, A. J., and S. N. Stechmann, 2009: The skeleton of tropical intraseasonal oscillations. Proc. Natl. Acad. Sci. USA, 106, 8417-8422, https://doi.org/10.1073/pnas.0903367106.

Maloney, E. D., A. H. Sobel, and W. M. Hannah, 2010: Intraseasonal variability in an aquaplanet general circulation model. $J$. $A d v$. Model. Earth Syst., 2, 24, https://doi.org/10.3894/JAMES.2010.2.5.

Matthews, A. J., 2008: Primary and successive events in the MaddenJulian Oscillation. Quart. J. Roy. Meteor. Soc., 134, 439-453, https://doi.org/10.1002/qj.224.

Morita, J., Y. N. Takayabu, S. Shige, and Y. Kodama, 2006: Analysis of rainfall characteristics of the Madden-Julian oscillation using TRMM satellite data. Dyn. Atmos. Oceans, 42, 107-126, https:// doi.org/10.1016/j.dynatmoce.2006.02.002.

Powell, S. W., and R. A. Houze Jr., 2015: Effect of dry large-scale vertical motions on initial MJO convective onset. J. Geophys. Res. Atmos., 120, 4783-4805, https://doi.org/10.1002/2014JD022961.

Ray, P., and C. Zhang, 2010: A case study of the mechanics of extratropical influence on the initiation of the Madden-Julian oscillation. J. Atmos. Sci., 67, 515-528, https://doi.org/10.1175/ 2009JAS3059.1.

Rowe, A. K., and R. A. Houze Jr., 2015: Cloud organization and growth during the transition from suppressed to active MJO conditions. J. Geophys. Res. Atmos., 120, 10324-10359, https:// doi.org/10.1002/2014JD022948.

Schneider, T., T. Bischoff, and G. H. Haug, 2014: Migrations and dynamics of the intertropical convergence zone. Nature, $\mathbf{5 1 3}$, 45-53, https://doi.org/10.1038/nature13636.

Seo, K.-H., 2003: Propagation and initiation mechanisms of the Madden-Julian oscillation. J. Geophys. Res., 108, 4384, https:// doi.org/10.1029/2002JD002876.

Sobel, A., and E. Maloney, 2013: Moisture modes and the eastward propagation of the MJO. J. Atmos. Sci., 70, 187-192, https:// doi.org/10.1175/JAS-D-12-0189.1.

Spencer, R. W., H. M. Goodman, and R. E. Hood, 1989: Precipitation retrieval over land and ocean with the SSM/I: Identification and characteristics of the scattering signal. J. Atmos. Oceanic Technol., 6, 254-273, https://doi.org/10.1175/1520-0426(1989)006<0254: PROLAO $>2.0 . \mathrm{CO} ; 2$.

Stephens, G. L., P. J. Webster, R. H. Johnson, R. Engelen, and T. L'Ecuyer, 2004: Observational evidence for the mutual regulation of the tropical hydrological cycle and tropical sea surface temperatures. J. Climate, 17, 2213-2224, https://doi.org/ 10.1175/1520-0442(2004)<2213:OEFTMR > 2.0.CO;2.

Vitart, F., 2009: Impact of the Madden Julian Oscillation on tropical storms and risk of landfall in the ECMWF forecast system. Geophys. Res. Lett., 36, L15802, https://doi.org/10.1029/ 2009GL039089.

Waliser, D. E., and C. Gautier, 1993: A satellite-derived climatology of the ITCZ. J. Climate, 6, 2162-2174, https://doi.org/ 10.1175/1520-0442(1993)006<2162:ASDCOT >2.0.CO;2.

, K. M. Lau, W. Stern, and C. Jones, 2003: Potential predictability of the Madden-Julian oscillation. Bull. Amer. Meteor. Soc., 84, 33-50, https://doi.org/10.1175/BAMS-84-1-33. 
Wang, B., and H. Rui, 1990: Dynamics of the coupled moist Kelvin-Rossby wave on an equatorial $\beta$-plane. J. Atmos. Sci., 47, 397-413, https://doi.org/10.1175/1520-0469(1990)047<0397: DOTCMK $>2.0 . \mathrm{CO} ; 2$.

Wang, C.-C., and G. Magnusdottir, 2006: The ITCZ in the central and eastern Pacific on synoptic time scales. Mon. Wea. Rev., 134, 1405-1421, https://doi.org/10.1175/MWR3130.1.

Wang, S., A. H. Sobel, and J. Nie, 2016: Modeling the MJO in a cloud-resolving model with parameterized large-scale dynamics: Vertical structure, radiation, and horizontal advection of dry air. J. Adv. Model. Earth Syst., 8, 121-139, https:// doi.org/10.1002/2015MS000529.

Wodzicki, K. R., and A. D. Rapp, 2016: Long-term characterization of the Pacific ITCZ using TRMM, GPCP, and ERA-Interim. J. Geophys. Res. Atmos., 121, 3153-3170, https://doi.org/10.1002/ 2015JD024458

Xu, W., and S. A. Rutledge, 2014: Convective characteristics of the Madden-Julian oscillation over the central Indian Ocean observed by shipborne radar during DYNAMO. J. Atmos. Sci., 71, 2859-2877, https://doi.org/10.1175/JAS-D-13-0372.1.

, and - 2015: Morphology, intensity, and rainfall production of MJO convection: Observations from DYNAMO shipborne radar and TRMM. J. Atmos. Sci., 72, 623-640, https://doi.org/10.1175/JAS-D-14-0130.1.

- - C. Schumacher, and M. Katsumata, 2015: Evolution, properties, and spatial variability of MJO convection near and off the equator during DYNAMO. J. Atmos. Sci., 72, 41264147, https://doi.org/10.1175/JAS-D-15-0032.1.
Yang, D., and A. P. Ingersoll, 2013: Triggered convection, gravity waves, and the MJO: A shallow-water model. J. Atmos. Sci., 70, 2476-2486, https://doi.org/10.1175/JAS-D-12-0255.1.

Yoneyama, K., C. Zhang, and C. N. Long, 2013: Tracking pulses of the Madden-Julian oscillation. Bull. Amer. Meteor. Soc., 94, 1871-1891, https://doi.org/10.1175/BAMS-D-12-00157.1.

Zhang, C., 2001: Double ITCZs. J. Geophys. Res., 106, 11785 11792, https://doi.org/10.1029/2001JD900046.

_ , 2005: Madden-Julian Oscillation. Rev. Geophys., 43, RG2003, https://doi.org/10.1029/2004RG000158.

_ 2013: Madden-Julian oscillation: Bridging weather and climate. Bull. Amer. Meteor. Soc., 94, 1849-1870, https://doi.org/ 10.1175/BAMS-D-12-00026.1.

— , and M. Dong, 2004: Seasonality in the Madden-Julian oscillation. J. Climate, 17, 3169-3180, https://doi.org/10.1175/ 1520-0442(2004)017<3169:SITMO > 2.0.CO;2.

- and J. Ling, 2017: Barrier effect of the Indo-Pacific Maritime Continent on the MJO: Perspectives from tracking MJO precipitation. J. Climate, 30, 3439-3459, https://doi.org/10.1175/ JCLI-D-16-0614.1.

Zhang, G. J., and X. Song, 2009: Interaction of deep and shallow convection is key to Madden-Julian Oscillation simulation. Geophys. Res. Lett., 36, L09708, https://doi.org/10.1029/ 2009GL037340.

Zuluaga, M. D., and R. A. Houze, 2013: Evolution of the population of precipitating convective systems over the equatorial Indian Ocean in active phases of the Madden-Julian oscillation. J. Atmos. Sci., 70, 2713-2725, https://doi.org/10.1175/JAS-D-12-0311.1. 